\title{
Application of Imaging Techniques to Determine the Post-Yield Behaviour of the Heterogeneous Microstructure of Friction Stir Welds
}

\author{
S. Ramachandran ${ }^{1}$ (I) A. K. Lakshminarayanan ${ }^{2} \cdot$ P. A. S. Reed ${ }^{3} \cdot$ J. M. Dulieu-Barton ${ }^{4}$
}

Received: 5 September 2020 / Accepted: 12 April 2021 / Published online: 21 April 2021

(c) The Author(s) 2021

\begin{abstract}
Background Friction Stir Welding (FSW) causes intense plastic deformation and consequent thermomechanical interactions resulting in a localised heterogeneous microstructure. To understand the weld mechanical behaviour, it is necessary to identify each microstructural sub-region in the weld.

Objective Determine the relationship between the local microstructure and mechanical behaviour of the different microstructural regions in a FSW.

Methods Scanning electron microscopy (SEM) identified the microstructural sub-regions of an FSW joint. A novel HighResolution Digital Image Correlation (HR-DIC) methodology enabled the determination of full-field strain response to provide the mechanical behaviour of the FSW sub-regions. X-ray computed tomography (CT) identified the geometry of the FSW and material composition.

Results The grain morphology in the FSW varied in the stir zone with a fine grain structure in the weld nugget and larger grains in the thermomechanical affected zone (TMAZ); the grains were larger in the retreating side (RS) compared to the advancing side (AS). Tungsten deposits were found in the weld nugget and attributed to tool wear. The mechanical properties of the weld subregions showed that the material in the stir zone had a greater yield strength than the base material and the RS of the FSW was much more ductile than the weld nugget and the AS side. The tungsten distributions in the stir zone correlated with the local mechanical behaviour.

Conclusions A novel methodology is developed that combines microstructural observations with HR-DIC enabling, for the first time, the FSW sub-region mechanical behaviour, to be related to the local grain morphology and inclusions caused by tool wear.
\end{abstract}

Keywords Stainless steel $\cdot$ Friction stir welding $\cdot$ Digital image correlation

S. Ramachandran

s.ramachandran@manchester.ac.uk

1 Department of Materials, The University of Manchester, Manchester M13 9PL, United Kingdom

2 Department of Mechanical Engineering, Sri Sivasubramaniya Nadar College of Engineering (Autonomous), Kalavakkam-603 103, Chennai, Tamilnadu, India

3 Engineering Materials Research Group, Faculty of Engineering and Physical Sciences, University of Southampton, Southampton SO17 1BJ, United Kingdom

4 School of Civil, Aerospace, and Mechanical Engineering, Bristol Composites Institute, University of Bristol, Bristol BS8 1TR, United Kingdom

\section{Introduction}

Friction Stir Welding (FSW) [1] is a solid-state welding technology that involves complex material flow and frictional heat to produce a weld using a non-consumable tool. Both the stirring action and intense plastic deformation of the FSW process commonly lead to a fine recrystallized microstructure formation in the weld nugget. The ability to produce solid-state welds with a low welding temperature and superior mechanical properties without producing any major weld defects has expanded the applications of FSW to a wide range of materials [2]. The complex thermomechanical effects of the FSW process can significantly modify the original material microstructure in the regions across the weld, which result in the formation of complex weld sub-regions known as the Heat Affected Zone (HAZ), 
Thermo-Mechanical Affected Zone (TMAZ) and weld nugget. As the weld sub-regions have distinct microstructures, the material behaviour across the FSW during and post-yield is governed by the non-uniform plastic deformation of the individual weld sub-regions [3]. Hence, to establish if the welding parameters have produced an efficient weld design, it is crucial to understand the link between these local microstructural and mechanical variations with the global mechanical response of the FSW weld. Additionally, information about the local property variations of the weld sub-regions are essential for both material and structural models of the weld performance $[4,5]$. Many traditional material characterisation techniques have been attempted to assess the local mechanical properties of the weld sub-regions, such as testing micro-size tensile specimens machined from the weld sub-regions [6] and instrumented ball indentation methods [7]. But all these techniques are time-intensive, and also the spatial resolution achieved from these techniques is insufficient to accurately determine the spatially varying local stress-strain behaviour across each weld sub-region.

DIC is a full-field imaging technique that enables the measurement of displacement and strain fields in the neighbourhood of welded joints [8-11]. Recently, there have been several well-documented investigations of the application of DIC to derive the local strain response of FSWs [3, 12-15]. Nevertheless, the post-yielding behaviour of the FSW subregions and the connection of this to the weld microstructure has not been studied in detail. Most of the previous DIC investigations confirmed the asymmetric strain distribution across the weld nugget $[16,17]$. However, the cause of this was not established as only low-resolution DIC optics were used, and there was no detailed correlation between the strains and the microstructure in the plastic loading regime. A key limitation arises from the necessity to machine test specimens to remove the thickness reduction across the weld nugget caused by the high axial force and plastic deformation between the tool and base materials. The machining procedure risks modifying the characteristics of the weld and in turn the local strain response. Therefore, it is more appropriate to perform the DIC measurements on the specimens that have not been machined. A procedure for compensating for the different thickness was developed in [18], and validated under the material's elastic response region.

A new procedure, based on the work in [18] is developed in the present paper so that the post-yield behaviour can be studied in detail. To the authors' knowledge, only one previous study [14] has used high-resolution DIC optics to study the post-yield behaviour of FSWs, but the local stress-strain response of the individual FSW weld sub-regions was not reported. DIC studies attempted to date on the FSW welds have been traditionally focused on the weld cross-section. However, in $[18,19]$, it was evident that both the FSW weld surface and cross-section have completely asymmetric microstructural features caused by the different levels of thermo-mechanical effects experienced during the FSW process. Therefore, it is necessary to examine the strain distribution on the weld surface in addition to that on the weld cross-section. In [18] it was confirmed that tungsten was present in the weld nugget caused by wear of the FSW tool, and also reported in [20-22]. In the present paper, the spatial distribution of tungsten over and throughout the entire stir zone is revealed using X-ray CT and linked to mechanical behaviour of the weld sub-region, by establishing the effect of tungsten on the local strain response of the stir zone.

The primary purpose of the work described in the present paper is to definitively classify the various FSW sub-regions and to extract post-yielding local stress-strain behaviour. To establish the microstructure-strength relationships, the local stress-strain behaviour obtained during plastic deformation is correlated with micrographs from the corresponding FSW sub-regions. Furthermore, both the complex material flow and tungsten distribution in the FSW weld nugget are traced in a high spatial resolution 3D X-ray CT characterisation. Thus enabling the effect of the spatial distribution of tungsten on the local stress-strain behaviour to be determined by correlating the DIC and X-ray CT results. Subsequently, a new insight is provided into the heterogeneous material response of the FSW stir zone by systematically correlating the findings from the High-Resolution Digital Image Correlation (HR-DIC) with the microscopy and the X-ray CT results.

\section{Test Specimens}

The base materials used in the investigation were 304 austenitic stainless steel (SS) sheets with dimensions of $139.6 \mathrm{x}$ $71.6 \times 2.0\left(\mathrm{~L} \mathrm{x} \mathrm{W} \mathrm{x} \mathrm{T)} \mathrm{mm}^{3}\right.$. The test specimens are identical to those used in [18], where full details of the chemical composition of the base materials and the FSW process parameters can be found. In summary, the welding direction was parallel to the rolling direction of the sheets and the tool material used was tungsten-1\% lanthanum oxide alloy with a convex shoulder and tapered cylindrical pin. The advancing (AS) and retreating sides (RS) of the tool with respect to the FSW (SS-SS) joint are shown in Fig. 1(a). The tensile specimens were machined according to ASTM E8/E8M-16a [23] by water jet cutting to the dimensions as shown in Fig. 1(a), with the weld nugget centred at the gauge section. In the mechanical testing the specimens were loaded in tension with the loading direction normal to the welding direction (WD). As a result of the FSW process the stir zone is thinner than the base material. Accurate dimensions of the specimen cross-section were measured using the Alicona focus variation microscope [18] and are shown in Fig. 1(b). The impact of the reduced cross-section is that when the 
Fig. 1 FSW (SS-SS) weld geometry: (a) Transverse tensile specimen machined from the FSW (SS-SS) joint, (b) Surface profilometry measurements of the stir zone - 3D view of specimen surface from the region indicated in (a) (a)

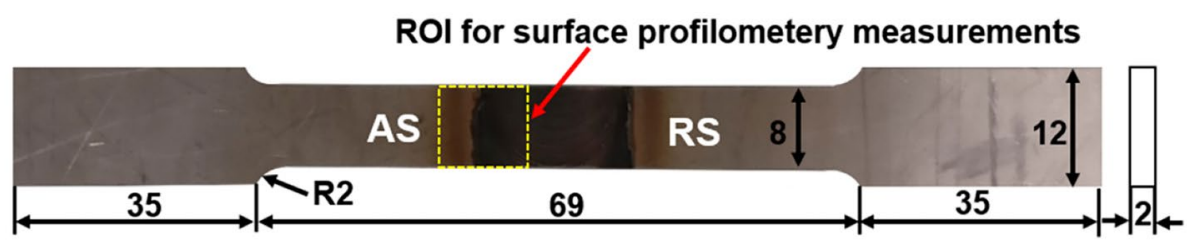

(b)

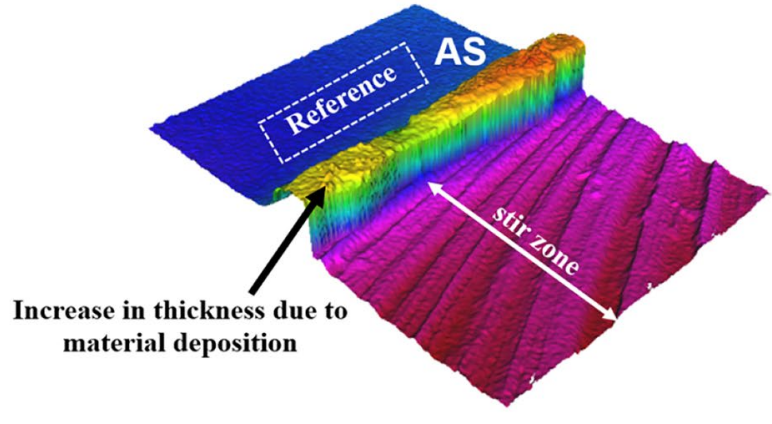

All dimensions are in $\mathrm{mm}$

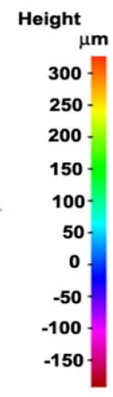

specimens are loaded in tension, an offset loading will be experienced across the stir zone section causing an out-ofplane bending strain in addition to the axial strain; this is discussed in more detail later in the paper.

\section{Materials Characterisation}

\section{Optical Microscopy}

Microstructures of the weld sub-regions were observed using an optical microscope (Make: Olympus, Tokyo, Japan; Model: BX51); The procedures for the preparation of metallographic specimens are described in [18]. The optical micrographs obtained in [18] are presented in Fig. 2 and are briefly described for reference here and for comparison to the more detailed SEM studies described in later sections of the paper. From the micrographs, it can be observed that the weld nugget (both surface and cross-section) have no major observable surface defects such as cracks, pores, or incomplete penetration. Base metal (BM) exhibits typical austenite grains with annealing twins. Due to the reduced heat input and high cooling rate of the FSW process [24], the narrow HAZ of the FSW weld located between the TMAZ and BM regions is not clearly observed in the optical micrographs and hence a greater resolution study was warranted. Fig. 2(b), (c) show the sharp interface between the weld nugget and TMAZ regions. In these figures, both the TMAZ regions (AS and RS) have a mixture of deformed elongated grains along the welding direction as well as partially recrystallized fine grains. However, the TMAZ located on the RS has a larger proportion of recrystallized fine grains compared to the TMAZ-AS. The FSW weld nugget is completely populated with the ultrafine recrystallized grains due to the dynamic recrystallization (DRX) mechanism offered by the frictional heat and intense plastic deformation effects associated with the FSW. This indicates that both the TMAZ regions (along both the AS and RS) have only partially experienced the DRX process due to the lack of frictional heat and plastic deformation. Fig. 2(d) reveals the weld nugget in the form of plastic flow of the material known as 'onion rings' [25].

\section{SEM Observations on FSW (SS-SS) Weld Sub-Regions}

Both SEM and SEM-EDS analysis were performed using a Field-emission gun scanning electron microscope (FEGSEM) (Make: JEOL, Model: 6500F). The SEM was equipped with an EDS system operated at different magnifications in both Secondary (SEI) and Backscattered electron modes (BEI) at an accelerating voltage of $15 \mathrm{kV}$. EBSD observations (HKL channel 5 acquisition system, Oxford Instruments) were carried out in the same SEM operated with an accelerating voltage of $20 \mathrm{kV}$ and probe current of $1.7 \mathrm{nA}$ at a working distance of $20 \mathrm{~mm}$. EBSD scans were performed using a step-size of $0.5 \mu \mathrm{m}$ to achieve the best spatial resolution during the EBSD analysis. All the EBSD scanned datasets were post-processed by the HKL Tango Map software for further quantitative analysis such as grain misorientation distributions and proportion of High-Angle Grain Boundaries (HAGBs) and Low-Angle Grain Boundaries (LAGBs).

Figure 3 presents the SEM micrographs of the FSW (SS-SS) weld sub-regions observed along the weld crosssection at a higher magnification than optical micrographs. The SS-BM (Fig. 3(a)) clearly shows austenite grains with an average grain size of $40-50 \mu \mathrm{m}$. In contrast to the optical microscopy observations, the SEM micrograph of SS-HAZ 
(a)
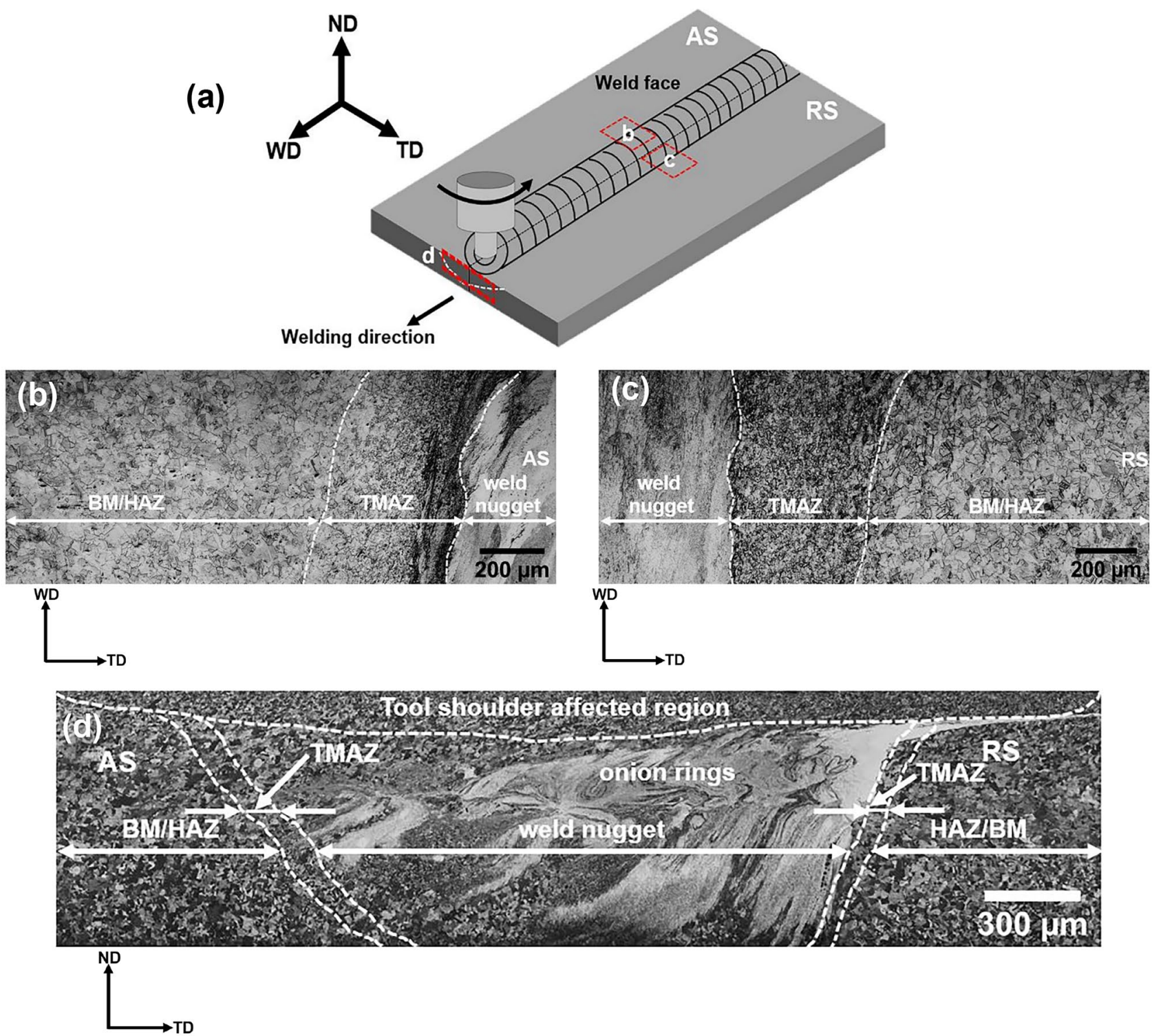

Fig. 2 Optical micrographs of the FSW (SS-SS) weld [18]: (a) Schematic representation of FSW (SS-SS) weld with the locations marked for optical microscopy; (b) Weld Face (AS); (c) Weld Face (RS); (d) Weld cross-section; (WD- Welding direction, ND- Normal direction, TDTransverse direction)

(Fig. 3(b)) shows a sharp difference in the grain size with the corresponding SS-BM. It appears that the SS-HAZ has achieved some grain growth, which confirms the presence of a minor HAZ due to the frictional heat generated from the FSW process. Fig. 3(c) shows a clear interface between the weld nugget and TMAZ as well as the TMAZ and HAZ regions along the RS of the weld cross-section. The plastically deformed grains located in the TMAZ have elongated along the direction of shear stress produced by the stirring effects of FSW tool. The plastic deformation caused by the FSW process severely compresses the pre-deformed coarse grains and produces very fine recrystallized equiaxed grains in the weld nugget (Fig. 3(d)). In addition to this, the DRX phenomenon which is expected to have been triggered by the adsorption of dislocations by subgrain boundaries may also have facilitated the nucleation and growth of ultrafine grains in the FSW weld nugget [25].

High magnification SEM micrography of the weld nugget (Fig. 3(e)) shows the deformed microstructure with several networks of submicron grains in the form of thin fragments. From Fig. 3(e), it is significant to note that both the size and orientation of the microstructure networks formed by the grouping of sub-micron grains are clearly distinct due to the differences in their plastic deformation rate gained from the FSW process. It has been reported [26] that the FSW process parameters, tool geometry, and axial force have a significant impact on the size 
Fig. 3 SEM Micrographs of the FSW (SS-SS) weld sub regions along cross-section: (a) SS-BM; (b) SS-HAZ; (c) Weld nugget/ TMAZ and TMAZ/HAZ interface; (d) Weld nugget; (e) Weld nugget (at high magnification); (f) Plastic material flow pattern (onion rings)
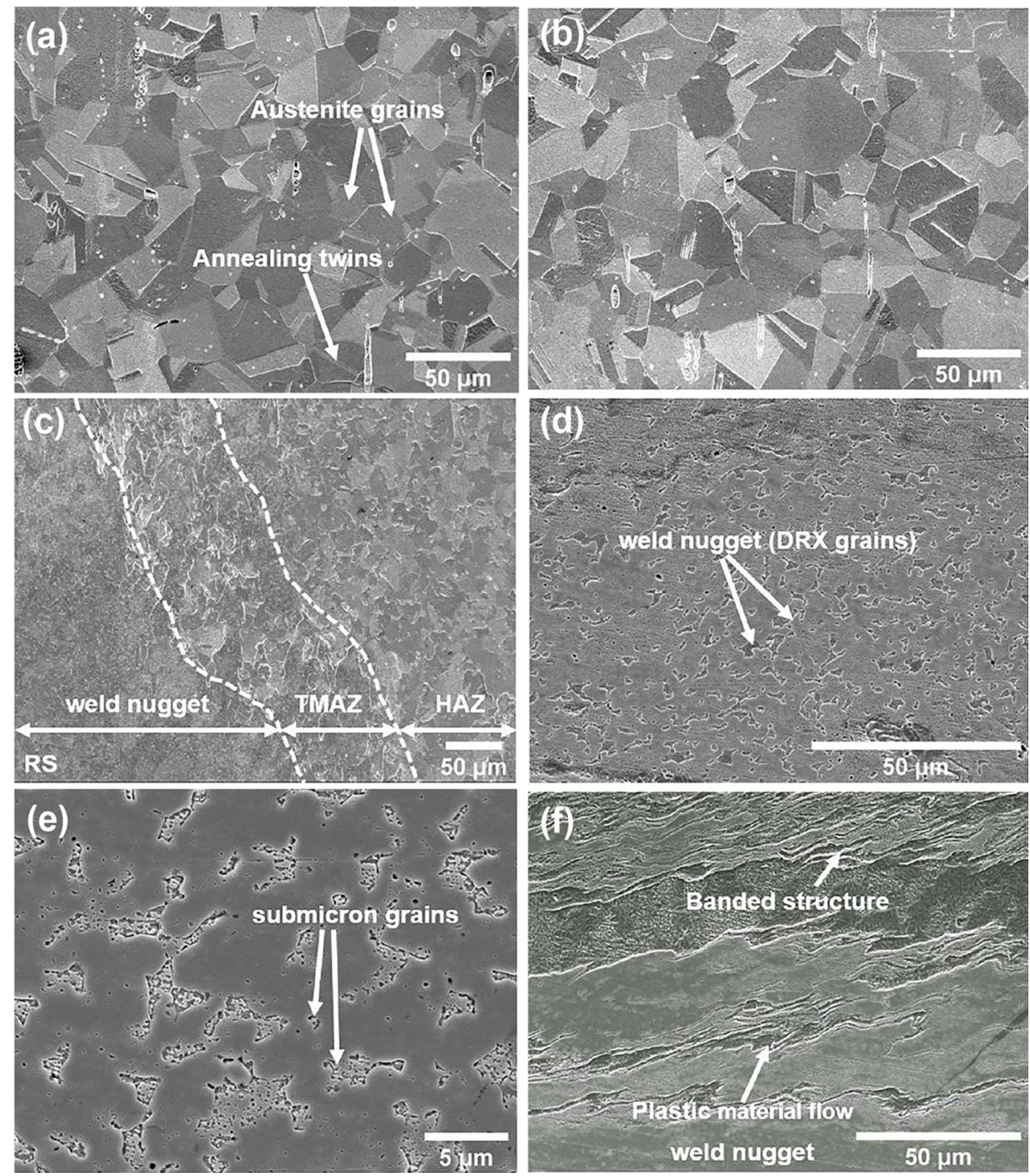

of recrystallized grains generated in the weld nugget. As per the Hall-Petch relationship, it is expected that the grain refinement achieved in the FSW weld nugget enhances the weld strength. Fig. 3(f) shows a series of closely spaced horizontal deformation bands in the form of the classical onion ring pattern adjacent to the weld nugget. The plastic deformation effects produced by the FSW parameters (tool rotation and welding speed) on the solidstate material leads to this complex material flow and grain size variations from the advancing to the retreating side.

\section{Elemental Analysis on FSW (SS-SS) Weld Interfaces}

The SEM-EDS analysis has only considered major elements, such as Iron $(\mathrm{Fe})$ and Tungsten (W) distributed on the FSW (SS-SS) weld nugget. The SEM-BSE (Backscattered Electron mode) micrographs shown in Fig. 4 show the heterogeneous elemental composition of the weld nugget. The contrast variations in the images captured at TMAZ/weld nugget interface (weld
face-Fig. 4(a), weld cross-section-Fig. 4(b)) are shown with corresponding EDS elemental maps of $\mathrm{Fe}$ and $\mathrm{W}$ represented in green and red colours, respectively. In [18] the elemental map of Fig. 4(b) was discussed briefly and only qualitatively, here a more detailed analysis of the data is performed. The wide compositional contrast variation between the $\mathrm{Fe}$ and $\mathrm{W}$ elements is evident in all the SEM-BSE micrographs. The results obtained from the EDS horizontal line scans across the weld interface are also shown in Fig. 4. In both line scans (Fig. 4(a), (b)), a sharp increase in the tungsten level is evident across the weld nugget. From the EDS maps of the weld face (Fig. 4(a)), it is noticed that the Fe is well mixed throughout the weld interface; but W distribution is highly concentrated only in the weld nugget. This dense population of tungsten present in the weld nugget can be attributed to tool wear as the tool is made from tungsten- $1 \%$ lanthanum oxide alloy material. The tungsten particles are removed from the tool and deposited in the weld nugget due to wear in the FSW process. It is also noticeable that the distribution of 

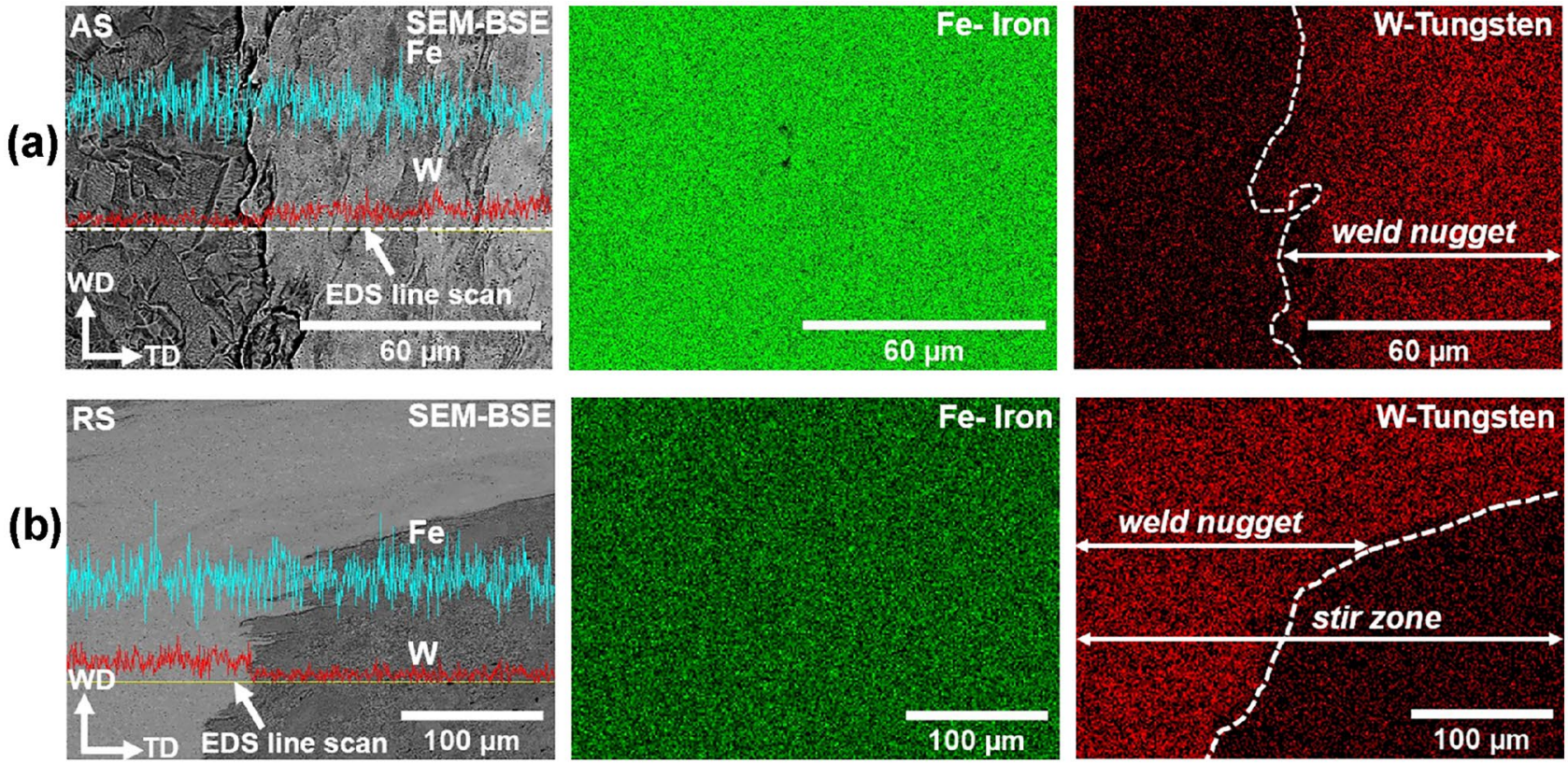

Fig. 4 SEM-EDS line profiles/micrographs captured at TMAZ/weld nugget interface of the FSW (SS-SS) weld: (a) along weld face; (b) along weld cross-section

tungsten along the weld cross-section (Fig. 4(b)) is only in the weld nugget (onion ring pattern). In the cross-sectional image, the weld nugget appears much brighter than the other weld subregions indicating a higher intensity of tungsten particles due to a severe frictional impact through the thickness of the weld. Tungsten has been found in the FSW weld nugget of strong, high melting point materials [20], because of the high rotational speeds and axial force of the FSW tool is required to generate sufficient frictional heat to plasticize the material in the solidstate without forming any defects [10]. The presence of tungsten particles in the weld nugget may have an effect on the mechanical properties of the weld nugget region, which is discussed in more detail in the later sections of the paper.

\section{SEM-EBSD Analysis}

Figure 5(a), (b), (c), (d) show the post-processed SEM-EBSD grain maps of the FSW (SS-SS) weld face captured on the AS and RS, respectively. Fig. 5(a), (c) are Inverse Pole Figures (IPF) which show the direction of the grain orientations, such as $\langle 100\rangle,\langle 110\rangle,\langle 111\rangle$, represented by the red, green, and blue colour coding scheme, respectively as displayed in a colour-coded triangle. All the intermediate orientations of grains are then coded by the mixture of RGB colours. From the IPF, it is observed that all the weld sub-regions (along AS and RS) have achieved more random orientations. Fig. 5(b), (d) are band contrast grain maps plotted with LAGBs and HAGBs.

To plot the LAGBs and HAGBs on the EBSD grain maps, a cut-off angle of $2^{\circ}$ was applied to exclude spurious grain boundaries and also to reduce the grain orientation noise in the misorientation distributions. Additionally, a general misorientation criterion was used to differentiate the LAGBs from the HAGBs. All grains with a misorientation angle in the range of $\left(2^{\circ}-15^{\circ}\right)$ were mapped as the LAGBs (shown in white colour), and the remaining grains $\left(>15^{\circ}\right.$-shown in red colour) were mapped as the HAGBs [13].

Figure 5(a) shows a wide range of grain distributions with a sharp spatial transition in grain size across the weld sub-regions. From the IPF, although the locations of weld sub-regions can be approximated based on their grain size, the exact boundary between the weld sub-regions cannot be clearly resolved. Here the weld sub-regions such as weld nugget, TMAZ, and HAZ can however be classified with a high degree of confidence based on the change in population density of LAGBs and HAGBs as displayed in Fig. 5(b). All the boundaries between the weld sub-regions as located in Fig. 5(b) have a step-change in the population density of HAGBs and LAGBs as well as the change in grain size. From Fig. 5(b), it is noticed that the FSW weld nugget on the AS has equiaxed sub-micron grains with a large number of grain boundaries. In addition to this, the weld nugget has an equal proportion of HAGBs and LAGBs. In theory, these fine HAGBs located in the weld nugget will act as barriers for dislocation movements and therefore will enable the weld nugget to achieve superior strength and toughness.

The high strain rate of the FSW process has effectively produced many dislocations within the grains in the weld nugget, which has in turn led to the growth of a high density of fine recrystallized grains. It is expected that the weld nugget will initially contain a significant number of sub-grain boundaries (misorientation $<2^{\circ}$ ) due to the intense plastic deformation. However, 

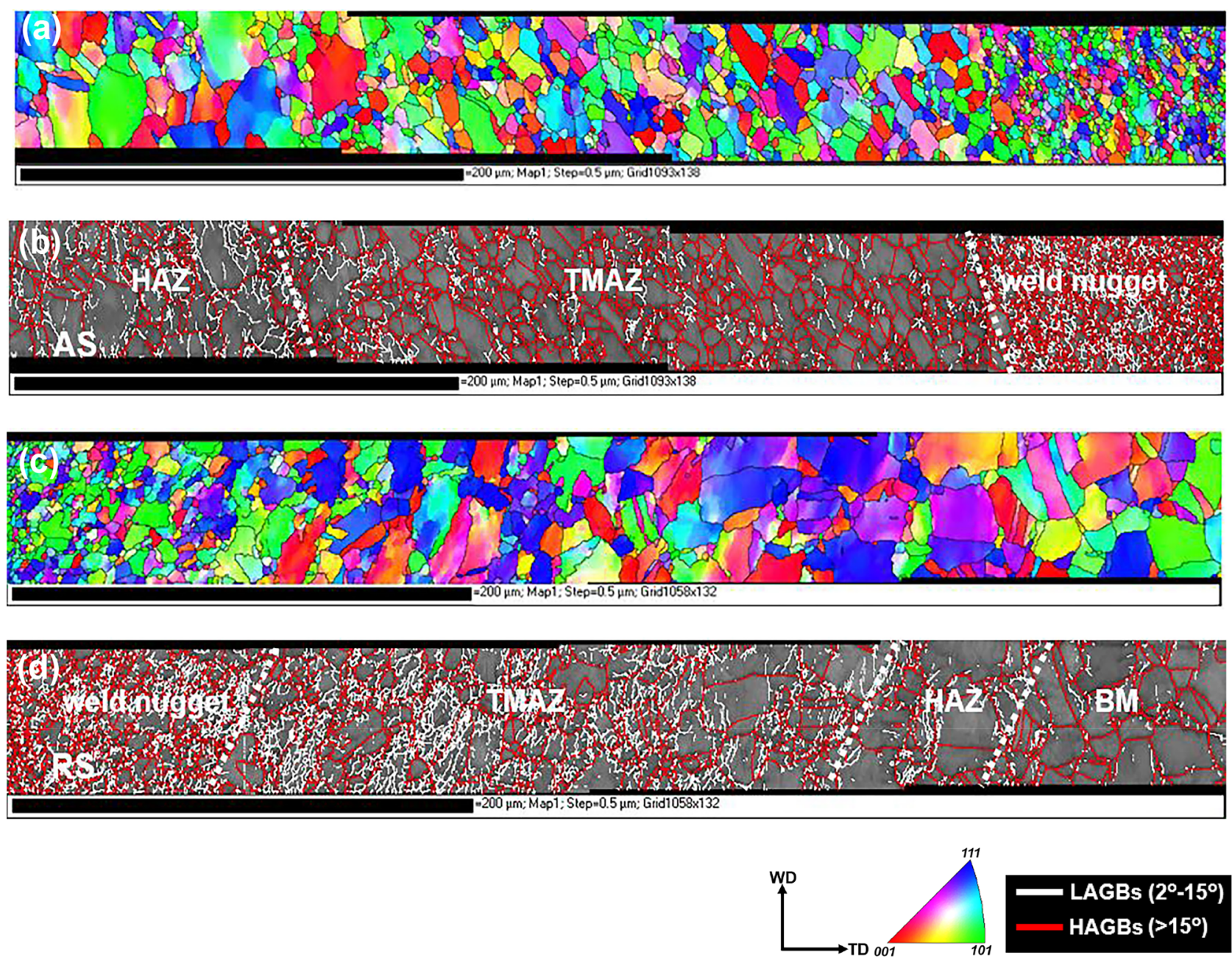

Fig. 5 SEM-EBSD post-processed micrographs of the FSW (SS-SS) weld face: (a) SEM-EBSD Inverse Pole Figure (IPF)- Weld Face (AS); (b) SEM-EBSD band contrast image mapped with LAGBs and HAGBs- Weld Face (AS); (c) SEM-EBSD Inverse Pole Figure (IPF)- Weld Face (RS); (d) SEM-EBSD band contrast image mapped with LAGBs and HAGBs- Weld Face (RS)

due to the extensive absorption of dislocations and the frictional heat, many sub-grain boundaries within the weld nugget will transform into LAGBs at the end of the DRX regime [22]. From the outer boundary of the weld nugget to TMAZ (Fig. 5(b)), it is seen that the misorientation angles of grain boundaries progressively increase and become HAGBs. The TMAZ on the AS consists of deformed and compressed elongated grains facing towards the shear (welding) direction; all the deformed grains have large segments of HAGBs. It can be seen that the majority of LAGBs distributed in the TMAZ have not completely developed into complete grain boundaries (Fig. 5(b)), which indicate that the TMAZ experienced a lower intensity of plastic deformation and didn't experience sufficient thermal energy for extensive recrystallization to occur. The HAZ can be differentiated by its coarse grains and significantly higher number of HAGBs rather than LAGBs. It is noteworthy that the TMAZ on the AS has only a very few LAGBs compared to the weld nugget and the HAZ. However, the TMAZ located on the RS (Fig. 5(d)) contains a high fraction of LAGBs. Additionally, the grains located in the TMAZ-RS (Fig. 5(c)) are much coarser than in the TMAZ-AS. The distribution of the LAGB and HAGB patterns for the other weld sub-regions such as the weld nugget, $\mathrm{HAZ}$ and the BM of the RS are very similar to that of the AS. Furthermore, on the $\mathrm{RS}$, the population of LAGBs is steadily increasing towards the direction of the weld nugget from the BM region. The above findings confirm that both the AS and RS regions of the weld face have experienced very different scales of plastic deformation and frictional heating during the FSW process.

\section{X-ray CT}

Although the SEM-EDS maps have confirmed the distribution of tungsten particles produced by FSW tool wear, the spatial distribution of tungsten particles over the entire weld nugget in 3D are not ascertained using SEM-EDS. 
Table 1 X-ray CT scan parameters

\begin{tabular}{ll}
\hline Parameter & In-house (Nikon/X-tek HMX) \\
\hline Sample thickness $(\mathrm{mm})$ & 2 \\
Operating voltage $(\mathrm{kV})$ & 200 \\
Beam current $(\mu \mathrm{A})$ & 110 \\
Voxel resolution $(\mu \mathrm{m})$ & 7.1 \\
Detector dimensions (pixels) & $2000 \times 2000$ \\
Scan time (hours) & $\sim 0.8$ \\
Number of projections & $2201\left(360^{\circ}\right.$ rotation $)$ \\
Number of frames & 8 \\
Exposure time $(\mathrm{sec})$ & 0.177 \\
\hline
\end{tabular}

Therefore, an X-ray CT characterisation technique to probe the spatial distribution of tungsten particles over the entire volume of the weld nugget as well as to achieve a clear understanding about the complex material flow across the weld was carried out. The findings obtained from the X-ray CT are compared with the DIC results and micrographs to provide a holistic understanding of the local strain gradients produced in various observed planes of the weld. The spatial distributions of Fe and W located in the FSW (SS-SS) weld can be resolved through an X-ray CT approach as both these elements have different X-ray attenuation rates, which will produce contrast in the tomographs. X-ray CT scan parameters used in this investigation are listed in Table 1.

All CT scans were performed using a custom Nikon X-tek HMX $225 \mathrm{KV}$ micro-focus CT system at the voxel resolution of $7.1 \times 7.1 \times 7.1 \mu \mathrm{m}^{3}$. The operating voltage and X-ray beam current used during the $\mathrm{CT}$ scans were $200 \mathrm{kV}$ and $110 \mu \mathrm{A}$, respectively. The CT data captured at an exposure time of $0.177 \mathrm{sec}$ was reconstructed from 8 frames and 2201 projections, which were evenly spaced over $360^{\circ}$. This reconstructed CT data was processed using the commercial software Avizolite 9.3 to allow 3D volume rendering analysis.

Figure 6 shows the CT scan results from the ROIs (Fig. 6(a)) of the FSW (SS-SS) specimen in a 3D representation. To better visualise the spatial distribution of different phases present in the reconstructed CT images, the grey level histogram of all the CT data is compared with the corresponding colour histogram (green) where the intensity range was fixed close to the maximum grey intensity value. From Fig. 6(b), (c), it can be seen that both AS and RS reconstructed images show different greyscale intensities in their surface. In these images, the brighter areas correspond to the regions of lower $\mathrm{X}$-ray transmission rate. It is noteworthy that the majority of these brighter spots are concentrated on the surface of the stir zone and appear to be closely aligned to the stir profiles of the FSW (SS-SS) specimen. Along the through-thickness cross-section (Fig. 6(d)), the brighter areas overlap with the onion ring pattern. The brighter and darker areas in the CT images are associated with the spatial distribution of tungsten (W) and iron (Fe), respectively. It is clear that $\mathrm{W}$ is deposited across the entire surface of the stir zone on the weld face, i.e. the tool shoulder region, but is also deposited through the thickness of the weld cross-section in a localised region on the retreating side in the weld nugget.
Fig. 6 X-ray CT scan results of the FSW (SS-SS) specimen: (a) ROIs for X-ray CT scan; (b) X-ray reconstructed image along AS; (c) X-ray reconstructed image along $\mathrm{RS}$; (d) X-ray reconstructed image along the weld crosssection (white/green regions of $\mathrm{X}$-ray radiographs indicate the tungsten distribution on the stir zone)

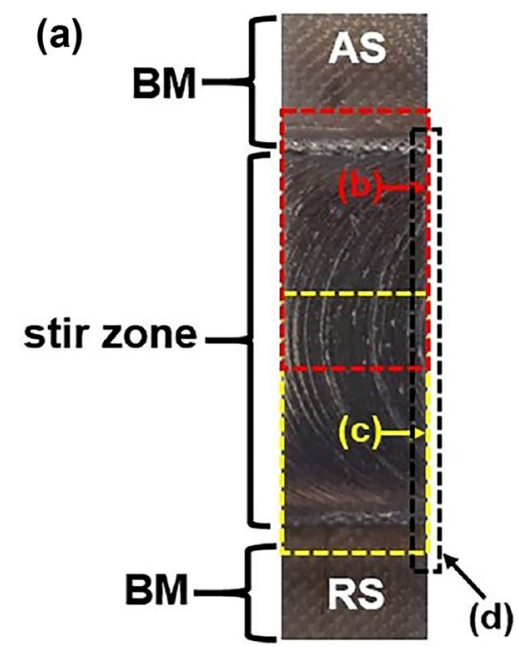

(b)

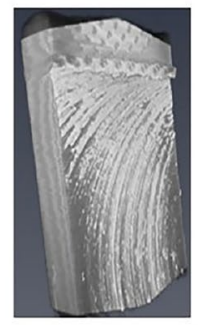

(c)

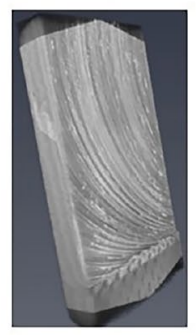

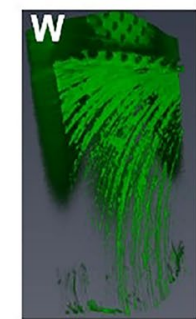

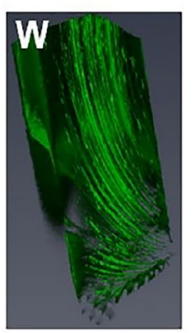

weld nugget

(d)

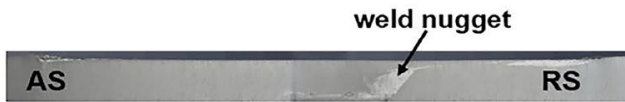




\section{HR-DIC}

\section{HR-DIC Experimental Set-Up}

For HR-DIC measurements, two tensile specimens machined from the FSW (SS-SS) joint named as S1 and S2 were tested. For S1, the HR-DIC strain measurements were performed on the Weld Face (WF) and Weld Root (WR) sides; for S2, the HR-DIC strain measurements were performed on the weld cross-sections (CS-1, CS-2). Figure 7 shows a photograph of the HR-2D DIC experimental set-up, which has two identical high-resolution DIC set-ups observing the front and rear of the test specimen at close stand-off distance. The main objective of using two HR DIC cameras is to perform HRDIC strain measurements simultaneously on both sides (front and rear) of the FSW(SS-SS) specimen to remove the parasitic strain caused by the out of plane displacements [18]. It is significant to note that this methodology can be applied both in the elastic and plastic loading range for S2 as the microstructure along the welding direction of an FSW weld can be considered to be relatively uniform apart from near to the start and finish positions. However, on the weld face and root surfaces (S1), this methodology can only be applied in the elastic range. This is because both the weld face and weld root regions have different microstructural features normal to the welding direction and hence have different yield points and subsequent hardening characteristics, so that as the material yields it cannot be expected that a simple averaging of the strains from the WF and WR faces can accurately account for the out of plane deformation. The HR 2D-DIC parameters used in this investigation are listed in Table 2.

In the HR-DIC experimental set-up, the DIC optics consists of 16 MP CCD camera (Make: LaVision, Germany;
Model: Imager Lx) having a resolution of 4904 x 3280 pixels fitted with a Canon MP-E65 mm focal length macro lens. Any image distortion caused by the macro lens was discounted in [18], as when taking multiple images that were stitched together, because of the small depth of field a rigid body motion was applied to the specimen rather than moving the camera. There was no evidence of any distortion in the images prior to stitching or any bias that might have resulted from distortion. Load data for each image captured during the DIC was recorded using an Analog to Digital Converter (ADC) channel (Make: National Instruments) synchronised with the DIC system. During uniaxial tensile tests, the specimen surface was strictly maintained perpendicular to the DIC camera sensor axis. All the uniaxial monotonic tensile tests were performed in an Instron-8800 servo-hydraulic testing machine (Make: Instron, UK) equipped with 10 $\mathrm{kN}$ load cell at room temperature. Table 3 shows the loading and unloading cycles applied on S1 and S2 specimens, respectively using the position control mode with a displacement rate of $0.2 \mathrm{~mm} / \mathrm{min}$. During DIC imaging, both the specimens were subjected to yielding through a sequential loading/unloading cycles with a load step of $0.5 \mathrm{kN}$. All the recorded HR-DIC images were correlated using commercial data correlation software LaVision (DaVis 8.3.1, LaVision, Germany). To determine the strain resolution of the DIC system, ten images were captured at zero load condition and processed using the DIC software. The average and standard deviation of the strain $\left(\varepsilon_{\mathrm{yy}}\right)$ from these images were determined. The standard deviation of the average strain calculated from the entire image was considered as the strain resolution of the DIC system. The subset and step sizes were chosen based on at least six speckles in the subset. The images at $2 \mathrm{kN}$ load step were then processed with

Fig. 7 HR-DIC experimental set-up

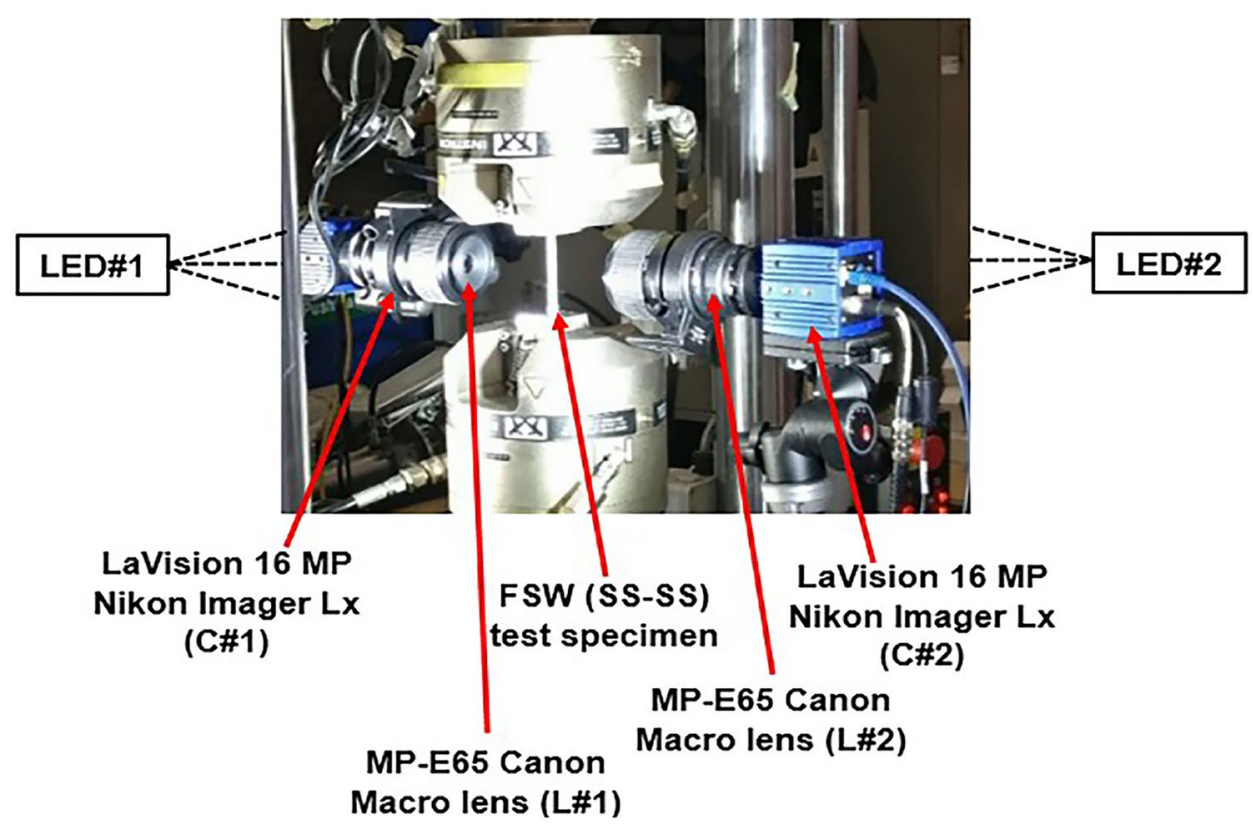


Table 2 HR 2D-DIC parameters

\begin{tabular}{lll}
\hline & Specimen-S1 (WF, WR) & Specimen-S2 (CS-1, CS-2) \\
\hline Technique used & 2D-DIC & 2D-DIC \\
Camera (Front and Rear) & $16 \mathrm{MP}$ LaVision Imager Lx & $16 \mathrm{MP}$ LaVision Imager Lx \\
Sensor and digitization & $4904 \times 3280,12 \mathrm{bit}$ & $4904 \times 3280,12 \mathrm{bit}$ \\
Lens (Front and Rear) & MP E-65 Canon Macro lens & MP E-65 Canon Macro lens \\
Lens magnification & $1 \mathrm{x}$ & $1 \mathrm{x}$ \\
Field of view & $16.4 \mathrm{~mm} \times 24 \mathrm{~mm}$ & $16.4 \mathrm{~mm} \times 24 \mathrm{~mm}$ \\
No of images captured & 2507 & 2503 \\
Correlation software & DaVis 8.3 .1 (LaVision) & DaVis 8.3 .1 (LaVision) \\
Subset, Step size & 59,20 & 39,10 \\
Interpolation, Shape functions, Correlation & $6^{\text {th }}$ order spline, $1^{\text {st }}$ order shape function, & $6^{\text {th }}$ order spline, $1^{\text {st }}$ order shape function, \\
$\quad$ criterion & Least square difference & Least square difference \\
Camera Frequency & $0.5 \mathrm{~Hz}$ & $0.5 \mathrm{~Hz}$ \\
Spatial resolution & $200 \mathrm{pixel} / \mathrm{mm}$ & 200 pixel/mm \\
Strain window & 3 data points & 3 data points \\
Strain resolution & $6.4390 \mathrm{x} 10^{-5}$ & $9.6209 \mathrm{x} 10^{-5}$ \\
\hline
\end{tabular}

different subsets and step sizes, until the strain converged to a theoretical value based on the applied load and a Young's modulus of $200 \mathrm{GPa}$. To obtain the best spatial resolution the smallest subset was chosen that gave the correct theoretical value.

\section{HR-DIC Results from Weld Face and Comparison To X-ray CT}

Figure 8(a) shows the strain maps $\left(\varepsilon_{\mathrm{yy}}\right)$ of weld face (WF) from $\mathrm{S} 1$ obtained at 5 and $6 \mathrm{kN}$. All strain maps derived from the WF show strain concentration across the stir zone due to the reduced thickness of the FSW weld nugget. The reduced thickness of the FSW specimen, causes bending due to offset loading when the specimen is subjected to a tension loading, as described in section 2 of the paper. This leads

Table 3 Loading/unloading cycles used for HR-DIC measurements

\begin{tabular}{lll}
\hline Cycle & Loading range $(\mathrm{kN})$ & Unloading range $(\mathrm{kN})$ \\
\hline 1 & 0 to $0.5 \mathrm{kN}$ & 0.5 to $0 \mathrm{kN}$ \\
2 & 0 to $1 \mathrm{kN}$ & 1 to $0 \mathrm{kN}$ \\
3 & 0 to $1.5 \mathrm{kN}$ & 1.5 to $0 \mathrm{kN}$ \\
4 & 0 to $2 \mathrm{kN}$ & 2 to $0 \mathrm{kN}$ \\
5 & 0 to $2.5 \mathrm{kN}$ & 2.5 to $0 \mathrm{kN}$ \\
6 & 0 to $3 \mathrm{kN}$ & 3 to $0 \mathrm{kN}$ \\
7 & 0 to $3.5 \mathrm{kN}$ & 3.5 to $0 \mathrm{kN}$ \\
8 & 0 to $4 \mathrm{kN}$ & 4 to $0 \mathrm{kN}$ \\
9 & 0 to $4.5 \mathrm{kN}$ & 4.5 to $0 \mathrm{kN}$ \\
10 & 0 to $5 \mathrm{kN}$ & 5 to $0 \mathrm{kN}$ \\
11 & 0 to $5.5 \mathrm{kN}$ & 5.5 to $0 \mathrm{kN}$ \\
12 & 0 to $6 \mathrm{kN}$ & 6 to $0 \mathrm{kN}$ \\
\hline
\end{tabular}

to a bending strain leading to a significant out of plane displacement during the HR-DIC measurements, and because only a single camera is used, parasitic strains are generated, as explained in [18]. Notwithstanding the effect of the bending strain, it can be seen that the strain localisation is maximum at the outer boundary of the stir zone (TMAZ) at all load values due to the sharp change in the cross-sectional area as evident in the X-ray CT images shown in Fig. 6.

From Fig. 8(a), it is evident that at $5 \mathrm{kN}$, the plastic strain is more highly pronounced on the TMAZ-RS than the TMAZ-AS. Mironova et al. [13] found the same result in their investigation. Therefore at the step-change in the area of cross-section at TMAZ-AS and TMAZ-RS regions, the displacement, and hence strain, are not the same due to the different amount of plastic deformation received in the AS and RS regions during the FSW process, because of the different hardening characteristics resulting from the different grain morphology in each region. This finding is corroborated by the EBSD micrographs. At $5 \mathrm{kN}$, the stir zone of the WF shows several strain concentration regions, which appear to be aligned with the stir profiles of the WF. As the stir zone has a considerable amount of tungsten particles from the tool wear (Fig. 4), it is considered that the local strain concentrations in the stir zone of the $\mathrm{WF}$ at $5 \mathrm{kN}$ result from the tungsten distribution. At $6 \mathrm{kN}$, it is observed that the centre of the stir zone along the WF shows a minimum strain in addition to the local strain concentration regions. This may be due to some crack propagation in the interface located in the WR.

Figure 8(a) correlates the DIC strain map of the weld face captured at $6 \mathrm{kN}$ with the corresponding X-ray CT reconstructed image obtained after the plastic deformation of the specimen. From this correlation, it is clearly revealed 
Fig. 8 HR-DIC results of the FSW (SS-SS)-S1 specimen along the weld face (WF): (a) DIC strain maps $\left(\varepsilon_{\mathrm{yy}}\right)$ captured at $5 \mathrm{kN}$ and $6 \mathrm{kN}$ and correlation with X-ray CT images; (b) Strain plots along the dotted vertical line of the WF as shown in (a) at different load values

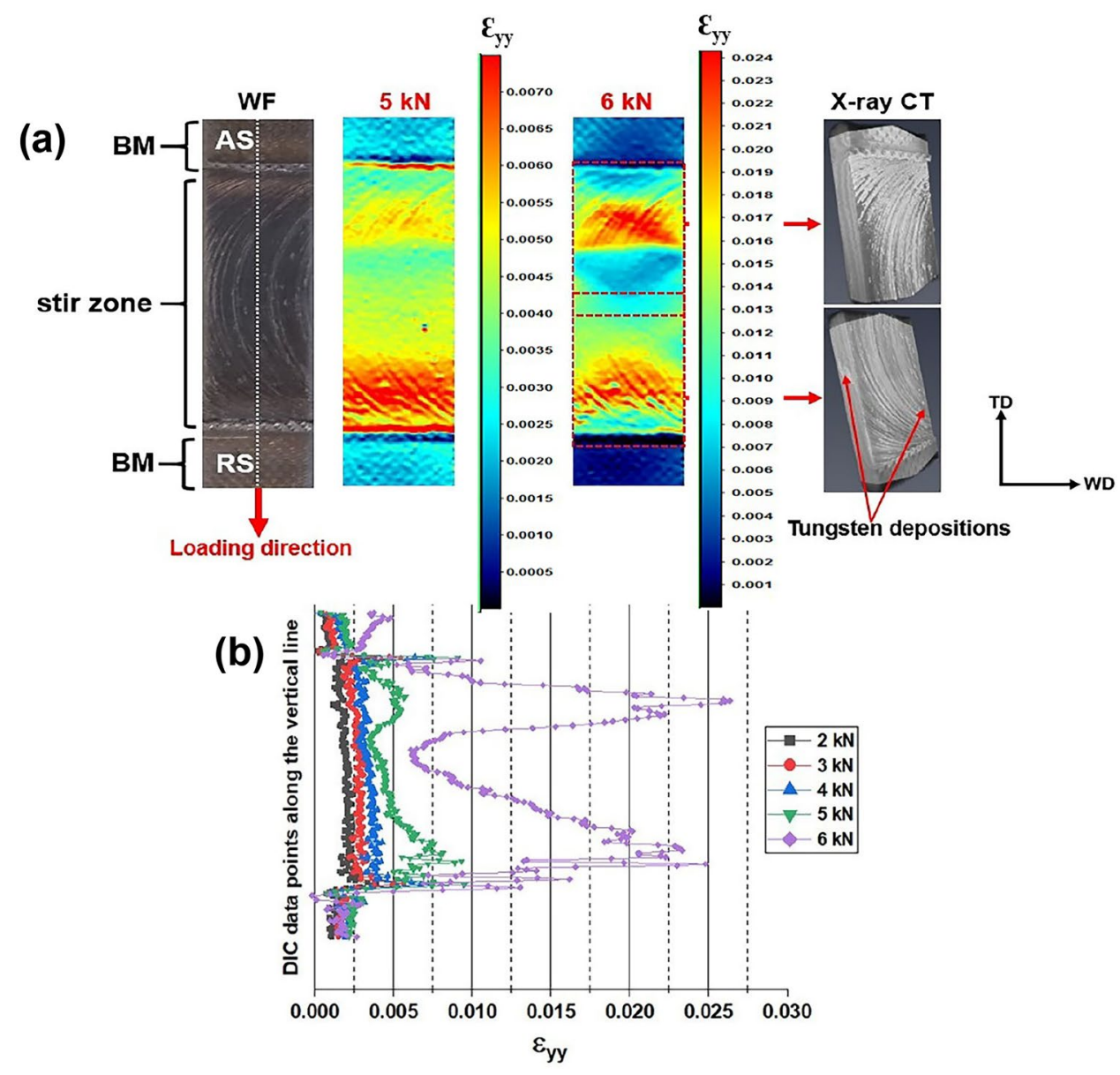

that the strain localisation observed in the HR-DIC strain map is closely linked to the localised spatial distribution of tungsten. Tungsten has a greater stiffness and yield strength than the stainless steel, but the inclusion of the particles has resulted in the strain localisation effects on the stir zone. Figure 8(b) shows the DIC strain plots extracted along the vertical line of the specimen at various load values along the WF. It can be seen that at the lower loads, below $5 \mathrm{kN}$, where the specimen is loaded elastically both the base metal regions (AS and RS) are carrying similar strains. In the stir zone, it can also be seen at the lower load levels the strains are uniform but greater than the base metal region because of the cross-section reduction and the offset loading. Once the elastic limit has been exceeded clear strain gradients are evident in the stir zone due to the strain hardening effects produced by the loading/unloading cycle applied to the specimen.

Figure 9(a) shows the strain maps $\left(\varepsilon_{y y}\right)$ of WR from S1 obtained at 5 and $6 \mathrm{kN}$. The effect of the localised bending resulting from the offset loading and the slight bend of the specimen has resulted in the negative strains in the strain maps. Importantly though, the WR strain maps show large strain concentrations along the weld centreline, i.e. the weld root. From the DIC plots at both 5 and $6 \mathrm{kN}$ in Fig. 9(a), it is seen that some additional strain concentrations emerge at the weld root, which could be attributed to cracking and led to reduced strain in the local region of stir zone, as shown in Fig. 8(a). Figure 9(b) shows a zoom-in of the DIC strain map of the weld root captured at $6 \mathrm{kN}$, which correlates well with the corresponding X-ray CT reconstructed image obtained after the plastic deformation of the specimen. It is clear that the crack along the weld root is in line with the strain localisation observed in the DIC strain map. Furthermore, the CT image also reveals the series of cracks located on the AS, and these cracks were responsible for additional strain concentrations in the weld root.

Figure 9(c) shows the strain plots extracted at various load values along the vertical line of the weld WR. All the line plots $(2,3,4$, and $5 \mathrm{kN})$ extracted from the WR confirm that the strain experienced by the weld sub-regions is very close to zero except at the weld interface. However, at $6 \mathrm{kN}$, the WR demonstrates a wide range of strain gradients across the rear face of the stir zone. Although the strain maps of the WF and WR regions show non-uniform strain in their elastic range, from Fig. 10, it is confirmed that the Young's modulus of the weld sub-regions calculated from the average 
Fig. 9 Correlation between the DIC strain map and X-ray CT reconstructed image of the weld root (WR): (a) DIC strain maps $\left(\varepsilon_{\mathrm{yy}}\right)$ captured at $5 \mathrm{kN}$ and $6 \mathrm{kN}$; (b) DIC strain map captured at $6 \mathrm{kN}$ with the corresponding $\mathrm{X}$-ray CT reconstructed image; (c) Strain plots along the dotted vertical line of the WR as shown in (a) at different load values (a)
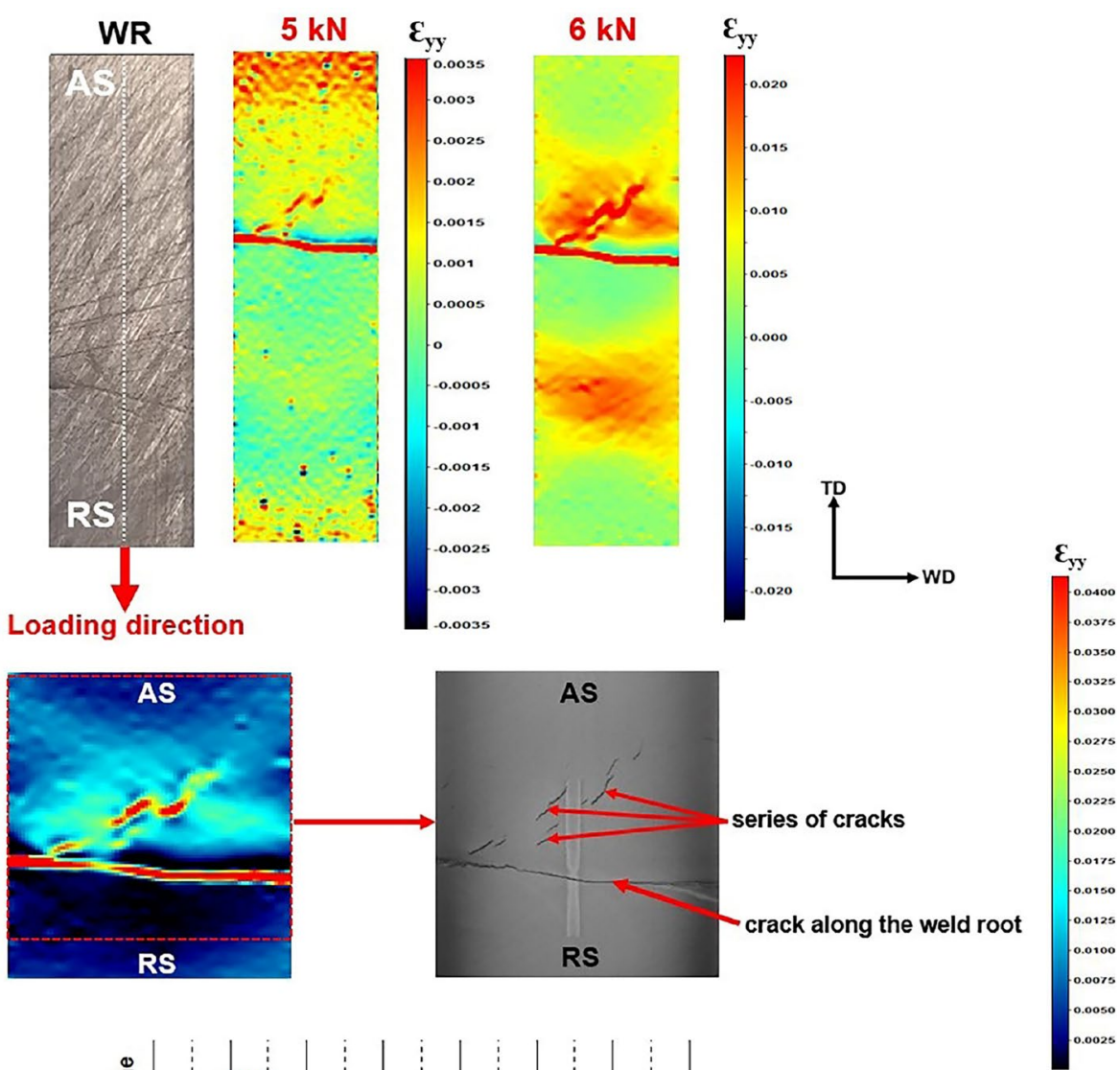

(b)
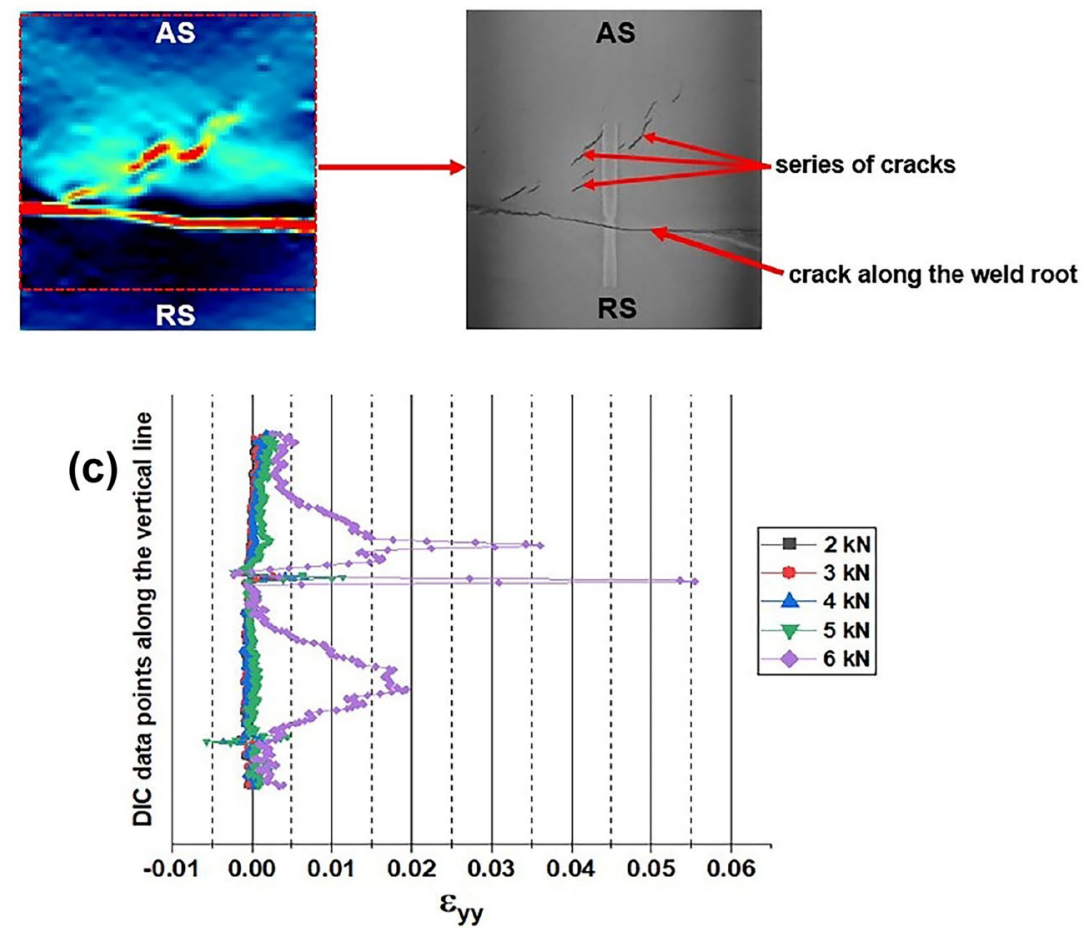

strain using the methodology described in [18] are correspond with the theoretical value. This finding again validates the methodology proposed in [18] where the parasitic strains and bending strains caused by the out of plane displacement are removed from the actual HR-DIC measurements by averaging the strains measured on the WF and WR regions in the material elastic region.

\section{HR-DIC Results from the Weld Cross-Section}

Figure 11(a) shows the strain maps of specimen S2 along the weld cross-sections (CS-1 and CS-2) at $2 \mathrm{kN}$. From these strain maps, it is apparent that the strain is consistently greater on one side of the specimen than the other.
As the specimens have a small cross-section of $8 \times 2 \mathrm{~mm}$ as well as reduced thickness across the weld nugget, and are relatively long, a small rotation of the specimen relative to the line of action of the applied load when mounting in the test machine grips as shown in Fig. 11(b) will produce in-plane bending. This may lead to substantial additional strains in HR-DIC measurements as a result of the in-plane bending. To assess the impact of any in-plane bending, Fig. 11(c) shows a free body diagram of the specimen under equilibrium conditions when it is rotated in the grips. From the free body diagram, the load $(P)$ can be resolved along the longitudinal $\left(P_{l}\right)$ and transverse $\left(P_{t}\right)$ direction and hence the constant applied moment resulting from the rotation of the specimen can be obtained. Therefore, at the outer edges of 


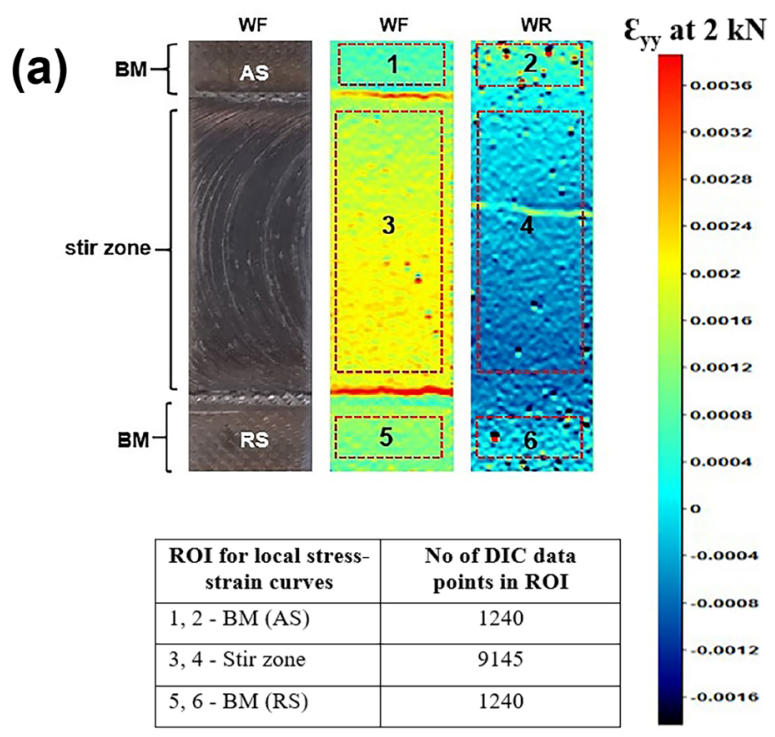

(b)

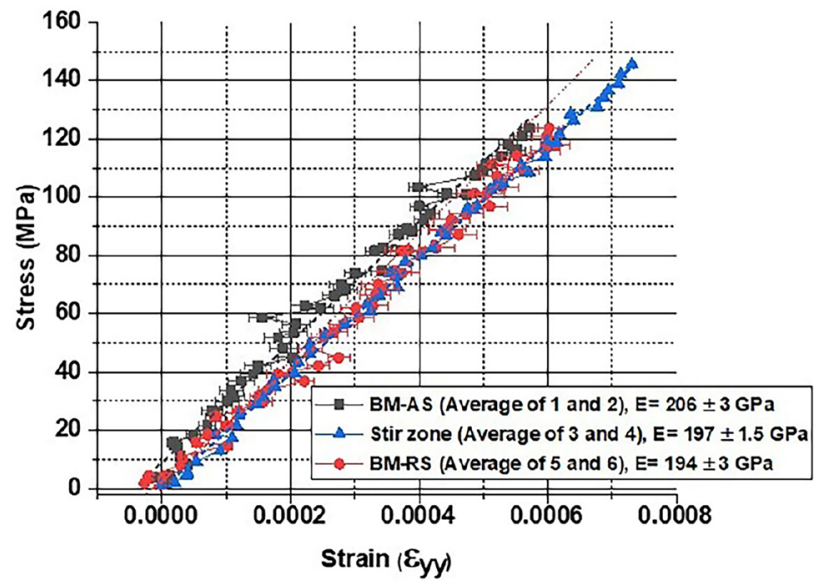

Fig. 10 HR-DIC strain in the elastic range of weld face: (a) ROIs to extract the local stress-strain curves, (b) Local stress-strain curves of the FSW (SS-SS) weld sub-regions

the specimen, the stress $(\sigma)$ is a combination of axial stress $\left(\sigma_{a}\right)$ and bending stress $\left(\sigma_{b}\right)$, as shown below:

$\sigma=\sigma_{a} \pm \sigma_{b}=\frac{P \cos \theta}{w t} \pm \frac{6 P \sin \theta l}{t w^{2}}$

where $\theta$ is the angle of the specimen to the line of action of the load, $l$ is the distance between grips, $w$ is the width of the specimen, and $t$ is the thickness of the specimen. Equation (1) shows that if the specimen is rotated by an angle $\theta$ the DIC strain measurements will be a combination of both axial and bending stresses. As $\theta$ is unknown, to assess the effect of the bending stress on the measured strains, it is necessary to set a range of values for which the rotation of the specimen would not be noticed by eye, hence $\theta$ was set to $-1^{\circ}$ to $+1^{\circ}$ to provide extreme values for the rotation of the specimen in the grips. Equation (1) was then used to calculate the stress for $\theta$ equal to $-1^{\circ}$ and $+1^{\circ}$ for a load of $2 \mathrm{kN}$, which is in the elastic range. The stress values are plotted in Fig. 11(d) using their corresponding strain determined using the Young's modulus of the stainless steel $(E=200 \mathrm{GPa})$.

As the stress-strain relationship is linear, then a line can be plotted between the two values shown by the dotted black line in Fig. 11(d). The DIC measured strain values obtained from the stir zone in CS1 and CS2 are shown in Figure 11d by the orange and red points, which indicates that a small rotation of around $0.5^{\circ}$ would account for the difference in the strains on CS1 and CS2. This amount of rotation is very small and difficult to avoid when clamping with hydraulic grips. Hence, it was decided to investigate if this difference could be accounted for by averaging the strain values from CS1 and CS2 by assuming uniform material conditions across the width of the specimen.
To extract the local stress-strain curves in the elastic range, the ROIs that include BM, Stir zone, and RS along the CS-1 and CS-2 regions are considered, as shown in Fig. 11(a). The local stress-strain curves are plotted in Fig. 12 using the average strain values and stress values determined using the cross-sectional area of the weld subregions obtained from the surface profilometry measurements [18]. Due to the reduced thickness of the stir zone, as shown in Fig. 1b, the stir zone has achieved a greater stress compared to other weld sub-regions. Figure 12 shows that the elastic modulus of the stir zone is very close to the theoretical value of $200 \mathrm{GPa}$. However, the elastic modulus of the BM-AS and BM-RS regions agree less well with their expected theoretical values. It should be considered that only a small region of the base material could be imaged close to the stress concentration caused by the change in section and this could explain the reason why these values do not correspond as well as those taken from the stir zone. It should also be considered that as only a small section of the BM (AS and RS) regions were covered, the scatter in the readings due to the stress concentration becomes more dominant. The results given in Fig. 10 show more consistent values for the BM regions, where more data points were used in the calculation of Young's modulus.

Figure 13(a) shows strain maps when the specimen is loaded beyond the elastic limit of the material to $5 \mathrm{kN}$ and $6 \mathrm{kN}$. These strain maps show that the material deforms in a nonlinear fashion with the applied stress. At $5 \mathrm{kN}$, the stir zone has achieved two major strain gradients along both cross-sections (CS-1 and CS-2). From CS-1 perspective, firstly, region 3 located in the central region of the 


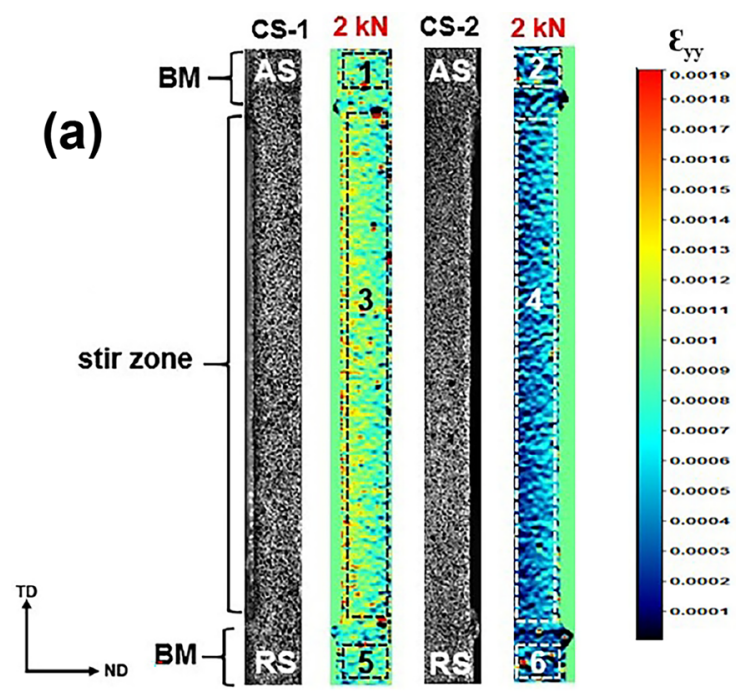

\begin{tabular}{|l|c|}
\hline $\begin{array}{c}\text { ROI for local stress- } \\
\text { strain curves }\end{array}$ & $\begin{array}{c}\text { No of DIC data } \\
\text { points in ROI }\end{array}$ \\
\hline 1,2 - BM (AS) & 1020 \\
\hline 3,4 - Stir zone & 10248 \\
\hline 5,6 - BM (RS) & 1020 \\
\hline
\end{tabular}

(b)

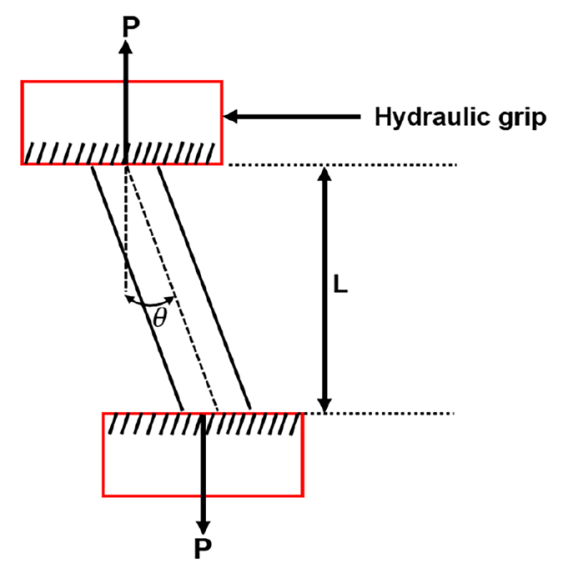

(c)

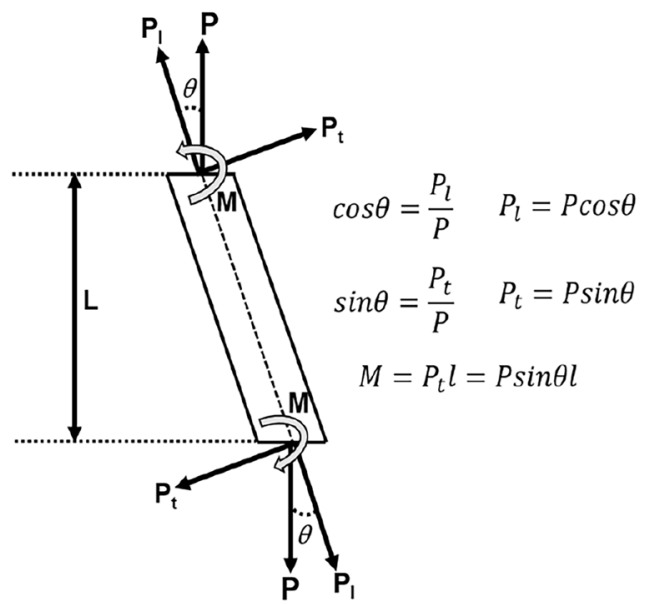

$\theta$... Angle of specimen to line of action of load

L... Distance between grips

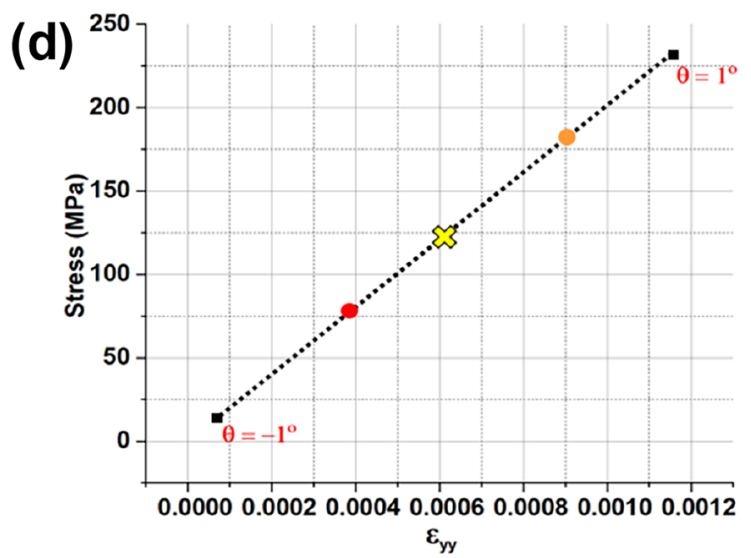

DIC measurement $\left(\theta=0.51^{\circ}, \varepsilon_{\mathrm{yy}}=0.00089, \sigma=178.17 \mathrm{MPa}\right)$ at $2 \mathrm{kN}(\mathrm{CS}-1)$

DIC measurement $\left(\theta=-0.4^{\circ}, \varepsilon_{y y}=0.00039, \sigma=79.18 \mathrm{MPa}\right)$ at $2 \mathrm{kN}(\mathrm{CS}-2)$

$\approx$ Average of (CS-1) and (CS-2)

Fig. 11 HR-DIC results from the FSW (SS-SS)-S2 specimen in the elastic loading range: (a) DIC strain maps $\left(\varepsilon_{\mathrm{yy}}\right)$ along the front weld crosssection (CS-1) and rear weld cross-section (CS-2) at $2 \mathrm{kN}$; (b) Schematic representation of in-plane bending caused by specimen rotation in the test machine grips; (c) Free body diagram with respect to (b) under equilibrium condition; (d) Stress-strain plots calculated using Equation (1) with respect to the FSW (SS-SS) tensile specimen misalignment at $2 \mathrm{kN}$

stir zone as well as region 2 located along the AS have a smaller strain compared to the BM. Secondly, the region 4 located in the stir zone have a substantial increase in strain compared to regions 2 and 3 . These findings establish the region 4 has reached its yield point at a lower load than regions 2 and 3. All these key observations from 


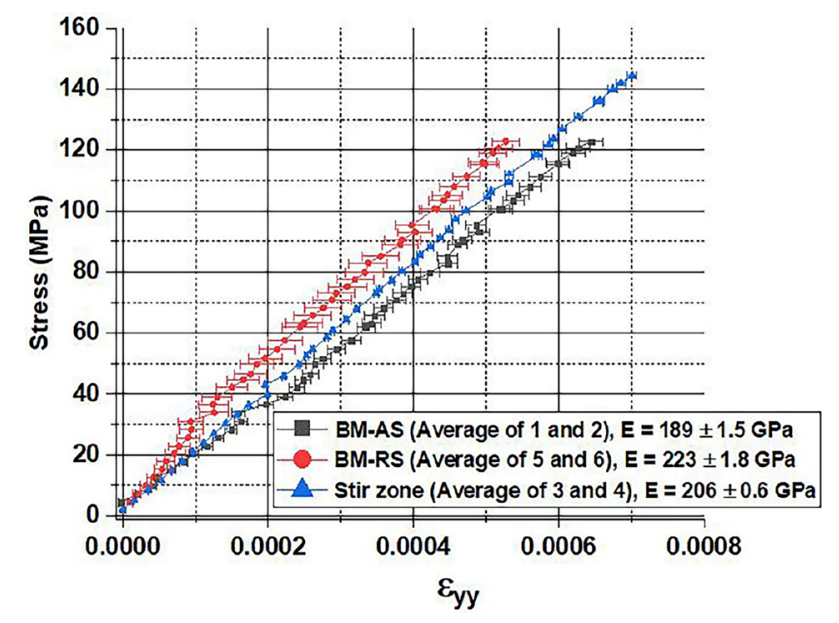

Fig. 12 Local stress-strain curves in the material elastic region (0 to $2 \mathrm{kN}$ load range) derived from the specimen (S2) using average strain values from the corresponding ROIs shown in Fig. 11 (a)

the $5 \mathrm{kN}$ strain map are also confirmed at the same locations in the strain map captured at $6 \mathrm{kN}$. Figure 13(b), (c) show the strain distribution at different load values along the vertical line of CS-1 and CS-2 regions (as shown in greyscale images), respectively. Both these figures show a similar trend where the strain distribution until $4 \mathrm{kN}$ is found to be uniform along the vertical line that includes all the major weld sub-regions such as BM, TMAZ and weld nugget. However, beyond $4 \mathrm{kN}$, the strains vary along the line due to the different material ductility beyond the material yield point.

\section{Microstructure-Mechanical Property Relationships}

To achieve a better understanding of the locally varying post-yield behaviour across the stir zone, Fig. 14 shows the strain map from the plastic deformed specimen at 6 $\mathrm{kN}$ load alongside the corresponding X-ray CT image. The reduced strain observed in region 3 (Fig. 14(a)) is due to the presence of the onion ring pattern which is densely populated with fine grains, confirmed by the micrograph shown in Fig. 2(d). Furthermore, in [18] it was shown that the weld nugget was harder than the (a)

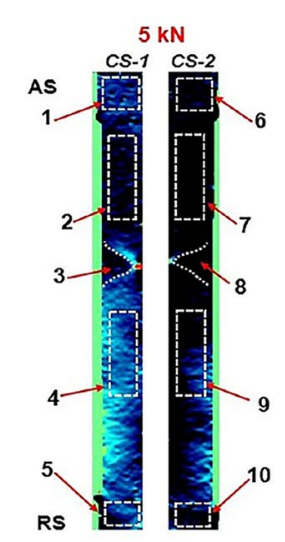

(b)

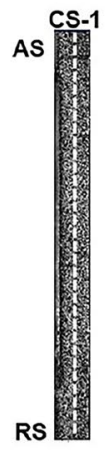

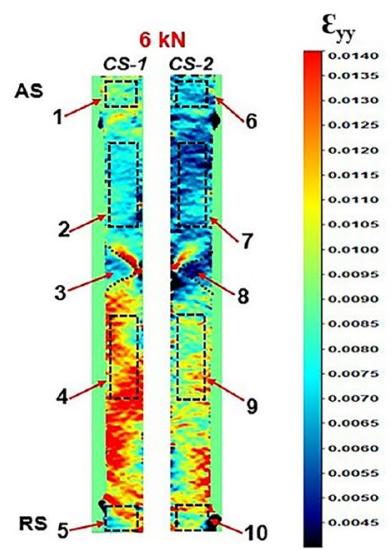

(c)

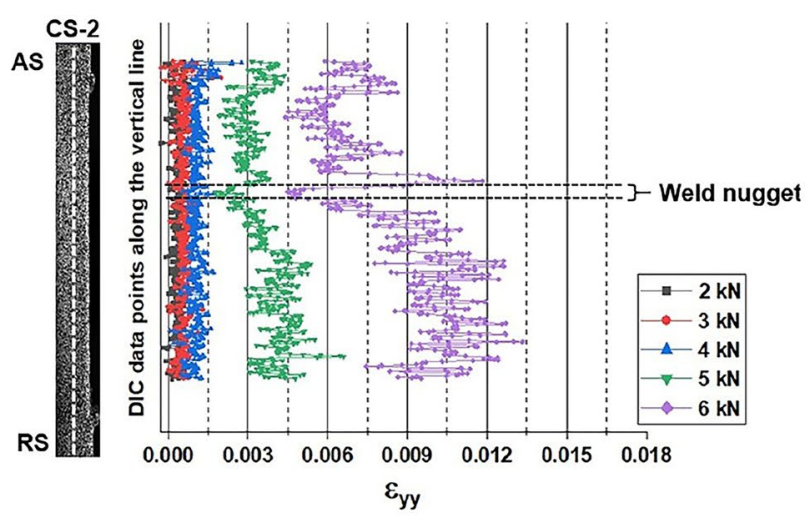

Fig. 13 DIC results of the FSW (SS-SS)-S2 specimen along the front weld cross-section (CS-1) and rear weld cross-section (CS-2) at plastic deformation: (a) DIC strain maps $\left(\varepsilon_{\mathrm{yy}}\right)$ captured at $5 \mathrm{kN}$ and $6 \mathrm{kN}$; (b) Strain plots along the vertical line of the CS-1 at different load values; (c) Strain plots along the vertical line of the CS-2 at different load values 
(a)

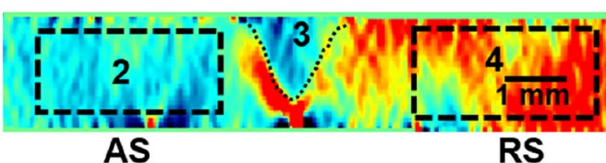

(b)

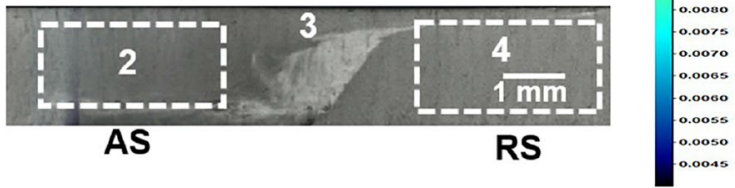

Fig. 14 DIC strain map correlation with X-ray CT: (a) $\varepsilon_{\mathrm{yy}}$ strain map of the FSW (SS-SS)-S2 along the weld cross-section at $6 \mathrm{kN}$; (b) X-ray CT reconstructed image of the FSW (SS-SS) weld crosssection-S2

remaining stir zone, which also explains the high resistance of region-3 to plastic deformation during tensile loading. In general, the expectation is that the entire stir zone should contain homogeneous fine recrystallized grains due to the plastic work developed in the FSW process [27]. However, the weld investigated here clearly has a range of grain sizes across the stir zone. The high strain concentration seen in the outer boundary of region 3 may be due to the mixture of coarse and fine grains. Much coarser grains located in region 4 compared to region 2 can be linked to the strain localisation observed along the RS. From Figs 14(b), 2(d), it is clearly seen that the through-thickness cross-section of the weld has a tungsten distributed through the thickness in the weld nugget and towards the AS at the weld root. It is clear that an increased strain is apparent in region 4 on the RS because of the larger grain size generated, with reduced strains in the weld nugget and on the advancing side. The reduced strains in the weld nugget (and the greater hardness [18]) could be attributed to the tungsten depositions inculcated into the fine grains. However, away from the surface of the stir zone there is clearly less tungsten on the advancing side, hence the reduced strain here cannot be attributed to the tungsten deposits.

By correlating DIC results with X-ray CT, it can also be seen that the strain localisation observed in region 4 of the weld cross-section (adjacent to the tungsten) is due to the nearby excessive amount of tungsten deposition in the form of material flow along the RS. During the FSW process, more friction is developed in the RS than the AS, as the tool movement is against the rotating direction. Therefore, the tool wear (tungsten particles) is more significant in the RS. Overall, the effect of tungsten on the strain distribution is more pronounced on the weld surface than in the through-thickness crosssection as the weld surface had a lower degree of grain refinement than the cross-section. The higher strength and stiffness tungsten particles deform less than the 304 stainless steel for the same given load causing localised strain concentrations and ultimately the cracks observed in Fig. 9 on the AS of the weld root. In Fig. 14(b) it can be seen that the tungsten deposits in the AS terminate in a location that corresponds with a strain localisation seen in Fig. 14(a).

To further demonstrate the effect of grain morphology on the mechanical behaviour of the joints, Fig. 15 shows the local stress-strain curves extracted from the weld cross-section in the plastic range from the ROIs, as shown in Fig. 13(a). The specimen was loaded firstly to $4 \mathrm{kN}$, and the yield strength of $222 \mathrm{MPa}$ was obtained for the base metal and $257 \mathrm{MPa}$ for the stir zone. It was not possible to identify the different weld regions in this load increment. Hence it was decided to unload the

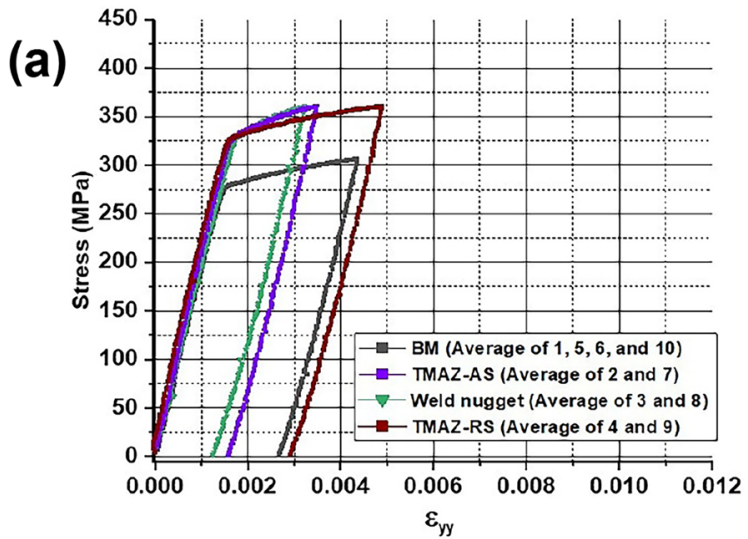

(b)

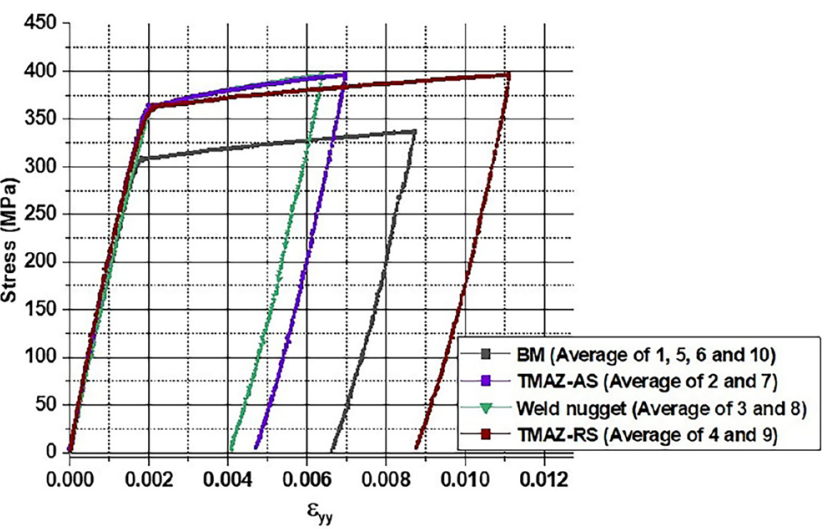

Fig. 15 Local stress-strain curves of the FSW (SS-SS)-S2 weld sub-regions in the material plastic region: (a) 0 to $5 \mathrm{kN}$ (loading) and $5 \mathrm{kN}$ to 0 $\mathrm{kN}$ (unloading); (b) 0 to $6 \mathrm{kN}$ (loading) and $6 \mathrm{kN}$ to $0 \mathrm{kN}$ (unloading) 
specimen and load to $5 \mathrm{kN}$ and unload (Fig. 15(a)) and then reload to $6 \mathrm{kN}$ and unloaded (Fig. 15(b)). The CS-1 and CS-2 regions were averaged to eliminate the effects of the small rotation of the specimen in the grips on DIC measurements (see Fig. 11). Additionally, the reduced thickness of the weld nugget is accounted for in all the local stress-strain curves. Figure 15 shows that the stressstrain response of TMAZ in the AS and RS are entirely different from one another due to the widely varying grain morphology and supports the observations made on the images in Fig. 14. The stir zone material has a similar yield strength that is greater than the base material and appears not to be dependent on the different microstructural characteristics and grain morphology. However, it is clear that after post-yielding, both the weld nugget and the TMAZ-AS had experienced less strain for the same stress than the BM and TMAZ-RS. The local high yield strengths achieved by the regions in the stir zone show that the FSW process has produced an over-matched stainless steel weld.

To illustrate the difference in mechanical behaviour Table 4 reports the yield strength after the initial load cycle, hardening parameter and permanent deformation recorded for each FSW sub-region for both loading regimes. The hardening parameter is the tangent to the stress-strain curve after yielding. In Table 4 it is clear that the yield strength is approximately the same across the stir zone and increases after the first loading cycle to the same level. The hardening parameter is substantially less in the TMAZ (RS) compared to the weld nugget and reduced by $50 \%$ after the first loading cycle. It is very clear that the permanent deformation and ductility in the TMAZ (RS) is much greater than the other weld sub-regions. In a complex structure, this may have significant implications such as initiating localised cracking as observed in the AS region of the test specimen.

Table 4 Mechanical properties of the weld sub-regions

\begin{tabular}{llll}
\hline Load range $(\mathrm{kN})$ & & 0 to 5 & 0 to 6 \\
\hline Yield strength (MPa) & BM & 276 & 306 \\
& TMAZ (AS) & 326 & 360 \\
& TMAZ (RS) & 326 & 360 \\
& Weld nugget & 328 & 360 \\
Hardening parameter (GPa) & BM & 52 & 34 \\
& TMAZ (AS) & 112 & 60 \\
& TMAZ (RS) & 65 & 38 \\
& Weld nugget & 122 & 55 \\
Permanent deformation & BM & 0.00123 & 0.00666 \\
& TMAZ (AS) & 0.00157 & 0.00471 \\
& TMAZ (RS) & 0.00294 & 0.00878 \\
& Weld nugget & 0.00124 & 0.00408 \\
\hline
\end{tabular}

\section{Conclusions}

By using a high-fidelity experimental methodology, the postyielding behaviour of the FSW weld sub-regions was correlated with the corresponding heterogeneous microstructure in the weld cross-section. Microstructure-property relationships of the weld sub-regions were established by aligning HR-DIC strain maps with a range of microscopy and X-ray CT images. Moreover, this investigation showed that tungsten particles were distributed in the weld stir zone due to tool wear, which had an effect on the local strain response across the weld. The key conclusions derived from this investigation are as follows:

- SEM observations showed different microstructural morphologies in the advancing and retreating sides of the weld face and cross-section.

- Both SEM-BSE micrographs and SEM-EDS elemental maps have established the presence of tungsten in the weld nugget. Hence, it is confirmed that significant tool wear occurred during the FSW process on the stainless steel.

- EBSD micrographs clearly identified the spatial location of various weld sub-regions with respect to the grain size as well as from the distribution of grain boundaries. EBSD results also differentiated the microstructural heterogeneities between the base material, weld nugget and the advancing and retreating sides of the weld.

- X-ray CT confirmed that the tungsten from the tool wear was mainly on the weld face but distributed through the thickness at the weld nugget.

- Overall, a good correlation between the local microstructural morphology and the corresponding strain response was obtained.

- The correlation of the HR-DIC strain maps with SEM micrographs confirmed that the reduced strain noticed in the weld nugget was due to the presence of fine recrystallized grains, but may also be attributed to the tungsten inclusions.

- From the correlation of the DIC strain map with X-ray CT results, the strain localisation profiles observed on the weld face were spatially aligned with the distribution of tungsten and indicated that the lower ductility in the weld nugget may be due to the tungsten inclusions.

- Post-yielding local stress-strain curves extracted from the weld cross-section found that the entire stir zone has a similar yield strength that is greater than the base material.

- Post-yield the retreating side of the weld has a much greater ductility than the advancing side and the weld nugget.

- The inclusion of tungsten appears to have caused local strain concentration in the stir zone of the weld face.

Acknowledgements The authors like to acknowledge the funding support provided by the Engineering and Physical Sciences Research Council (EPSRC) through a research grant (EPSRC Reference: EP/R031711/1). 
The experimental work described in the paper was conducted in the Testing and Structures Research Laboratory (TSRL) at the University of Southampton (https://www.southampton.ac.uk/engineering/research/ facilities/tsrl.page). The authors are grateful for the support received from Andrew Robinson, the TSRL Principal Experimental Officer. The authors also thank the Department of Mechanical Engineering, Sri Sivasubramaniya Nadar College of Engineering (Autonomous), Tamilnadu, India for supplying the FSW test specimens.

\section{Declarations}

Conflict of Interest The authors have no conflicts of interest to declare that are relevant to the content of this article.

Open Access This article is licensed under a Creative Commons Attribution 4.0 International License, which permits use, sharing, adaptation, distribution and reproduction in any medium or format, as long as you give appropriate credit to the original author(s) and the source, provide a link to the Creative Commons licence, and indicate if changes were made. The images or other third party material in this article are included in the article's Creative Commons licence, unless indicated otherwise in a credit line to the material. If material is not included in the article's Creative Commons licence and your intended use is not permitted by statutory regulation or exceeds the permitted use, you will need to obtain permission directly from the copyright holder. To view a copy of this licence, visit http://creativecommons.org/licenses/by/4.0/.

\section{References}

1. Thomas WMNED, Needham JC, Temple-Smith P, Kallee SW, Dawes CJ (1995) Friction Stir Welding. UK Patent GB 2.306266

2. Nilesh Kumar WY, Mishra RS (2015) Friction Stir Welding of Dissimilar Alloys and Materials Butterworth-Heinemann

3. Leitão C, Galvão I, Leal RM, Rodrigues DM (2012) Determination of local constitutive properties of aluminium friction stir welds using digital image correlation. Mater Des 33:69-74. https://doi.org/10.1016/j.matdes.2011.07.009

4. Saranath KM, Sharma A, Ramji M (2014) Zone wise local characterization of welds using digital image correlation technique. Opt Lasers Eng 63:30-42. https://doi.org/10.1016/j.optlaseng.2014.06.006

5. Sierra G, Wattrisse B, Bordreuil C (2008) Structural Analysis of Steel to Aluminum Welded Overlap Joint by Digital Image Correlation. Exp Mech 48(2):213-223. https://doi.org/10.1007/ s11340-007-9112-2

6. Velu M, Bhat S (2013) Metallurgical and mechanical examinations of steel-copper joints arc welded using bronze and nickelbase superalloy filler materials. Mater Des 47:793-809. https:// doi.org/10.1016/j.matdes.2012.12.073

7. Ambriz RR, Chicot D, Benseddiq N, Mesmacque G, de la Torre SD (2011) Local mechanical properties of the 6061-T6 aluminium weld using micro-traction and instrumented indentation. Eur J Mech - A/Solids 30(3):307-315. https://doi.org/10. 1016/j.euromechsol.2010.12.007

8. Saranath KM, Ramji M (2015) Local zone wise elastic and plastic properties of electron beam welded Ti-6Al-4V alloy using digital image correlation technique: A comparative study between uniform stress and virtual fields method. Opt Lasers Eng 68:222234. https://doi.org/10.1016/j.optlaseng.2015.01.005

9. Saranarayanan R, Lakshminarayanan AK, Venkatraman B (2019) A combined full-field imaging and metallography approach to assess the local properties of gas tungsten arc welded copper-stainless steel joints. Arch Civil Mech Eng 19(1):251-267. https://doi.org/10.1016/j.acme.2018.08.009

10. Li H, Dai QL, Shi QY (2015) Experimental Study on the Heterogeneity of Mechanical Properties of Friction Stir Welded Joints with the Digital Image Correlation Method. Strength Mater 47(1):80-86. https://doi.org/10.1007/s11223-015-9631-5

11. Sutton MA, Matta F, Rizos D, Ghorbani R, Rajan S, Mollenhauer DH, Schreier HW, Lasprilla AO (2017) Recent Progress in Digital Image Correlation: Background and Developments since the 2013 W M Murray Lecture. Exp Mech 57(1):1-30. https://doi.org/10. 1007/s11340-016-0233-3

12. Reynolds AP, Duvall F (1999) Digital image correlation for determination of weld and base metal constitutive behaviour. Weld Res Suppl 78(10):355-360

13. Mironov S, Sato YS, Yoneyama S, Kokawa H, Fujii HT, Hirano S (2018) Microstructure and tensile behavior of friction-stir welded TRIP steel. Mater Sci Eng A 717:26-33. https://doi.org/10.1016/j. msea.2018.01.053

14. Texier D, Zedan Y, Amoros T, Feulvarch E, Stinville JC, Bocher $P$ (2016) Near-surface mechanical heterogeneities in a dissimilar aluminum alloys friction stir welded joint. Mater Des 108:217229. https://doi.org/10.1016/j.matdes.2016.06.091

15. Louëdec GL, Pierron F, Sutton MA, Reynolds AP (2012) Identification of the Local Elasto-Plastic Behavior of FSW Welds Using the Virtual Fields Method. Exp Mech 53(5):849-859. https://doi. org/10.1007/s11340-012-9679-0

16. Hiscocks J, Diak BJ, Gerlich AP, Daymond MR (2018) Strain localisation and failure of dissimilar magnesium-based alloy friction stir welds. Sci Technol Weld Joi 1-7. https://doi.org/10.1080/ 13621718.2018.1450704

17. Besel Y, Besel M, Alfaro Mercado U, Kakiuchi T, Hirata T, Uematsu Y (2017) Influence of local fatigue damage evolution on crack initiation behavior in a friction stir welded $\mathrm{Al}-\mathrm{Mg}-\mathrm{Sc}$ alloy. Int J Fatigue 99. Part 1:151-162. https://doi.org/10.1016/j. ijfatigue.2017.02.024

18. Ramachandran S, Lakshminarayanan AK, Reed PAS, Dulieu-Barton JM (2019) Development of High-Fidelity Imaging Procedures to Establish the Local Material Behavior in Friction Stir Welded Stainless Steel Joints. Metals 9(5):592

19. Li WY, Li JF, Zhang ZH, Gao DL, Chao YJ (2013) Metal Flow during Friction Stir Welding of 7075-T651 Aluminum Alloy. Exp Mech 53(9):1573-1582. https://doi.org/10.1007/ s11340-013-9760-3

20. Kumar SS, Murugan N, Ramachandran KK (2018) Microstructure and mechanical properties of friction stir welded AISI 316L austenitic stainless steel joints. J Mater Process Technol 254:79-90. https://doi.org/10.1016/j.jmatprotec.2017.11.015

21. Zhang H, Wang D, Xue P, Wu LH, Ni DR, Xiao BL, Ma ZY (2018) Achieving ultra-high strength friction stir welded joints of high nitrogen stainless steel by forced water cooling. J Mater Sci Technol 34(11):2183-2188. https://doi.org/10.1016/j.jmst.2018.03.014

22. Li H, Yang S, Zhang S, Zhang B, Jiang Z, Feng H, Han P, Li J (2017) Microstructure evolution and mechanical properties of friction stir welding super-austenitic stainless steel S32654. Mater Des 118:207-217. https://doi.org/10.1016/j.matdes.2017.01.034

23. ASTM E8 / E8M-16a (2016) Standard Test Methods for Tension Testing of Metallic Materials, ASTM International, West Conshohocken, PA. https://www.astm.orghttps://doi.org/10.1520/E0008_E0008M-16A

24. Nandan R, Debroy T, Bhadeshia H (2008) Recent advances in friction-stir welding - Process, weldment structure and properties. Prog Mater Sci 53(6):980-1023. https://doi.org/10.1016/j.pmatsci. 2008.05.001

25. Prangnell PB, Heason CP (2005) Grain structure formation during friction stir welding observed by the 'stop action technique.' Acta Mater 53(11):3179-3192. https://doi.org/10.1016/j.actamat.2005. 03.044 
26. Niu PL, Li WY, Vairis A, Chen DL (2019) Cyclic deformation behavior of friction-stir-welded dissimilar AA5083-to-AA2024 joints: Effect of microstructure and loading history. Mater Sci Eng A 744:145-153. https://doi.org/10.1016/j.msea.2018.12.014

27. Mishra RS, Ma ZY (2005) Friction stir welding and processing. Mater Scie Eng R: Reports 50(1-2):1-78. https://doi.org/10. 1016/j.mser.2005.07.001
Publisher's Note Springer Nature remains neutral with regard to jurisdictional claims in published maps and institutional affiliations. 